\title{
lonospheric convection response to slow, strong variations in a northward interplanetary magnetic field: A case study for January 14, 1988
}

Article

Published Version

Knipp, D. J., Emery, B. A., Richmond, A. D., Crooker, N. U., Hairston, M. R., Cumnock, J. A., Denig, W. F., Rich, F. J., de la Beaujardiere, O., Ruohoniemi, J. M., Rodger, A. S., Crowley, G., Ahn, B. -H., Evans, D. S., Fuller -Rowell, T. J., Friis -Christensen, E., Lockwood, M., Kroehl, H. W., Maclennan, C. G., McEwin, A., Pellinen, R. J., Morris, R. J., Burns, G. B., Papitashvili, V., Zaitzev, A., Troshichev, O., Sato, N., Sutcliffe, P. and Tomlinson, L. (1993) lonospheric convection response to slow, strong variations in a northward interplanetary magnetic field: A case study for January 14, 1988. Journal of Geophysical Research, 98 (A11). pp. 19273-19292. ISSN 0148-0227 doi: https://doi.org/10.1029/93JA01010 Available at https://centaur.reading.ac.uk/38819/

It is advisable to refer to the publisher's version if you intend to cite from the work. See Guidance on citing. 
All outputs in CentAUR are protected by Intellectual Property Rights law, including copyright law. Copyright and IPR is retained by the creators or other copyright holders. Terms and conditions for use of this material are defined in the End User Agreement.

\section{$\underline{\text { www.reading.ac.uk/centaur }}$}

\section{CentAUR}

Central Archive at the University of Reading

Reading's research outputs online 


\title{
Ionospheric Convection Response to Slow, Strong Variations in a Northward Interplanetary Magnetic Field: A Case Study for January 14, 1988
}

\author{
D. J. KNipp, ${ }^{1}$ B. A. EMery, ${ }^{2}$ A. D. Richmond, ${ }^{2}$ N. U. Crooker, ${ }^{3}$ M. R. Hairston, ${ }^{4}$ \\ J. A. Cumnock, ${ }^{4}$ W. F. Denig, ${ }^{5}$ F. J. Rich, ${ }^{5}$ O. DE LA Beaujardiere, ${ }^{6}$ J. M. Ruohoniemi, ${ }^{7}$ \\ A. S. Rodger,${ }^{8}$ G. Crowley, ${ }^{8}$ B.-H. AhN, ${ }^{10}$ D. S. Evans, ${ }^{11}$ T. J. Fuller-Rowell,${ }^{11}$ \\ E. Fris-Christensen, ${ }^{12}$ M. LockWood ${ }^{13}$ H. W. Kroehl, ${ }^{14}$ C. G. MaClennan, ${ }^{13}$ A. McEwin, ${ }^{16}$ \\ R. J. Pellinen, ${ }^{17}$ R. J. Morris, ${ }^{18}$ G. B. Burns, ${ }^{18}$ V. Papitashvili, ${ }^{19}$ A. Zaitzev, ${ }^{10}$ \\ O. Troshichev, ${ }^{20}$ N. Sato, ${ }^{21}$ P. Sutcliffe, ${ }^{22}$ and L. Tomlinson ${ }^{23}$
}

\begin{abstract}
We analyze ionospheric convection patterns over the polar regions during the passage of an interplanetary magnetic cloud on January 14, 1988, when the interplanetary magnetic field (IMF) rotated alowly in direction and had a large amplitude. Using the assimilative mapping of ionospheric electrodynamics (AMIE) procedure, we combine simultaneous observations of ionospheric drifts and magnetic perturbations from many different instruments into consistent patterns of high-latitude electrodynamics, focusing on the period of northward IMF. By combining satellite data with ground-based observations, we have generated one of the most comprehensive data sets yet assembled and used it to produce convection maps for both hemispheres. We present evidence that a lobe convection cell was embedded within normal merging convection during a period when the IMF $B_{y}$ and $B_{z}$ components were large and positive. As the IMF became predominantly northward, a strong reversed convection pattern (afternoon-to-morning potential drop of around $100 \mathrm{kV}$ ) appeared in the southern (summer) polar cap, while convection in the northern (winter) hemisphere became weak and disordered with a dawn-to-dusk potential drop of the order of $30 \mathrm{kV}$. These patterns persisted for about 3 hours, until the IMF rotated significantly toward the west. We interpret this behavior in terms of a recently proposed merging model for northward IMF under solstice conditions, for which lobe field lines from the hemisphere tilted toward the Sun (summer hemisphere) drape over the dayside magnetosphere, producing reverse convection in the summer hemisphere and impeding direct contact between the solar wind and field lines connected to the winter polar cap. The positivo IMF $B_{x}$ component present at this time could have contributed to the observed hemispheric asymmetry. Reverse convection in the summer hemisphere broke down rapidly after the ratio $\left|B_{y} / B_{z}\right|$ exceeded unity, while convection in the winter hemisphere strengthened. A dominant dawn-to-dusk potential drop was established in both hemispheres when the magnitude of $B_{y}$ exceeded that of $B_{z}$, with potential drops of the order of $100 \mathrm{kV}$, even while $B_{2}$ remained northward. The later transition to southward $B_{x}$ produced a gradual intensification of the convection, but a greater qualitative change occurred at the transition through $\left|B_{y} / B_{z}\right|=1$ than at the transition through $B_{z}=0$. The various convection patterns we derive under northward IMF conditions illustrate all possibilities previously discussed in the literature: nearly single-cell and multicell, distorted and symmetric, ordered and unordered, and sunward and antisunward.
\end{abstract}

\section{INTRODUCTION}

An interplanetary magnetic cloud passed the Earth on January $14-15,1988$, resulting in very pronounced signatures in the high-latitude ionospheric convection patterns. Coincidentally, a coordinated ionospheric observational campaign was taking place under the global ionospheric simultaneous measurements of substorms (GISMOS)

\footnotetext{
1 Department of Physics, U.S. Air Force Academy, Colorado.

2 High Altitude Observatory, NCAR, Boulder, Colorado.

Atmospheric Science Department, UCLA, Los Angeles, California.

- University of Texas at Dallas, Richardson.

5 Phillips Laboratory, Hanscom AFB, Massachusetts.

- SRI International, Menlo Park, California.

7 Johns Hopkins University Applied Physics Laboratory, Laurel, Maryland.

British Antarctic Survey, Cambridge, England.

- Center for Atmospheric Research, University of Massachusetts, Lowell.
}

Copyright 1993 by the American Geophysical Union.

Paper number 93JA01010.

0148-0227/93/93JA-01010\$05.00 program. A large number of instruments were operating in both hemispheres, measuring the convection and its geomagnetic effects as well as the ionospheric conductivity and the fluxes of precipitating auroral particles. We have applied the assimilative mapping of ionospheric electrodynamics (AMIE) procedure [Richmond and Kamide, 1988; Richmond, 1992] to the data from these instru-

\footnotetext{
${ }^{10}$ Kyungpook National University, Taegu, Korea.

11 Space Environment Laboratory, NOAA, Boulder, Col-

12 Danish Meteorological Institute, Copenhagen, Denmark.

1s Rutherford-Appleton Laboratory, Chilton, Didcot, Oxon, England.

is National Geophysical Data Center, Boulder, Colorado.

${ }^{15}$ AT\&T Bell Laboratories, Murray Hill, New Jersey.

16 Bureau of Mineral Resources, Canberra, Australia.

${ }^{27}$ Finnish Meteorological Institute, Helsinki.

18 Australian Antarctic Division, Kingston, Tasmania.

10 IZMIRAN, Troitsk, Moscow.

20 Arctic and Antarctic Research Institute, St. Petersburg, Russia.

${ }^{21}$ National Institute of Polar Research, Tokyo, Japan.

23 Hermanus Magnetic Observatory, Hermanus, South Africa.

23 Institute of Geological and Nuclear Sciences Ltd., Christchurch, New Zealand.
} orado. 
ments in order to estimate the high-latitude convection patterns as they responded to the changing interplanetary magnetic field (IMF). The derived convection patterns contain a wealth of information relating to solar-windmagnetospheric-ionospheric coupling processes. The present paper focuses on coupling during northward IMF conditions and explores the implications of the derived patterns for models of the coupling processes during periods when the solar wind IMF varied slowly. This study goes well beyond the earlier studies of this period by Knipp et al. [1993] in convection pattern analysis.

Other studies of this interval have already shed significant light on the magnetosphere-ionosphere response to the strong solar wind forcing associated with the magnetic cloud. Cumnock et al. [1992] have provided a detailed analysis of the convection of the early hours of January 14, 1988, and have discussed a mechanism for the evolution of a reverse two-cell convection pattern during the 0400-0800 UT interval. A trilogy of papers by Freeman et al. [1993] and Farrugia et al. [1992a, b] present an overview of the magnetic cloud structure and its magnetospheric and ionospheric effects, including estimates of the cross polar cap voltage from the DMSP F-8 ion drift data alone. The independent investigations discussed in that trilogy and in Knipp et al. [1993], have concluded that: (1) strong reverse convection with sunward flow in the southern (summer) polar cap developed during the interval of northward $\mathrm{B}_{2}$; (2) simultaneously weak, distorted convection existed in the northern (winter) polar cap; (3) the summer hemisphere ion flow was strong and well ordered while the winter hemisphere ion flow was unordered with large velocity shears while $B_{z}$ was positive and large; (4) the $B_{y}$ component contributed to significant noon/midnight flow assymmetries; (5) the high-latitude convection strengthened as the ratio $\left|\mathrm{B}_{\mathrm{y}} / \mathrm{B}_{\mathrm{z}}\right|$ became large; and (6) under strong IMF $B_{y}$ conditions convection flow patterns reverted to a near-normal two-cell configuration. Additionally, Freeman et al. [1993] reported a change in the dawn-dusk asymmetry of the southern hemisphere reverse convection pattern associated with the changing $B_{y}$ component and investigated the subsequent polar cap dynamics as $B_{2}$ turned southward. Farrugia et al. [1993b] focused on the substorm activity associated with the southward portion IMF portion of the cloud.

While the large-scale configuration of convection is relatively well understood when the IMF is southward (see review by McPherron [1991]), it is not well understood for northward IMF. Recent reviews by Burke [1989], Troshichev [1990], and Moses and Reiff [1993] offer examples of many different convection configurations for northward IMF: single-cell and multicell, distorted cells and symmetric cells, ordered and unordered, and sunward and antisunward flow over the polar caps. Although numerous investigators have provided insights into this plethora of convection patterns and have related many of the variations in convection to variations in the IMF components, much controversy still exists over the apparent multimode nature of the patterns.

It is widely believed that magnetospheric-ionospheric convection is driven largely by the merging of the IMF with geomagnetic field lines at the magnetopause, by merging in the magnetotail, and to a lesser extent by some viscouslike processes at the magnetopause that are still poorly understood [e.g., Siscoe, 1991]. When the IMF is southward (negative IMF $\mathrm{B}_{\mathbf{z}}$ ), magnetic merging can occur between the
IMF and the northward closed geomagnetic field lines on the dayside magnetopause, as first proposed by Dungey [1961]. For northward IMF (positive $\mathrm{B}_{\mathbf{2}}$ ), Russell [1972] proposed that merging occurs on open geomagnetic field lines extending from the polar caps into the geotail, resulting in lobe convection that stirs field lines in the polar caps but does not produce any net transfer of magnetic flux between open and closed flux regions. Alternatively, northward IMF may merge with closed field lines poleward of the cusps, as first proposed by Dungey [1963]. Merging topologies for northward IMF are reviewed by Crooker [1992].

Northward IMF has often been associated with geomagnetically quiet conditions. Hoffman et al. [1988] describe periods of extreme quiescence associated with positive $B_{2}$ values of less than $1 \mathrm{nT}$. However, as the $B_{2}$ component increases beyond $1 \mathrm{nT}$, quiet conditions can give way to vigorous convection. Such vigorous convection can be inferred from Israelevich et al. [1988] who reported electric field strengths in excess of $100 \mathrm{mV} / \mathrm{m}$ in sunward convecting plasma. Knipp et al. [1991] have estimated a potential drop across the polar cap in a reverse convection situation to be of the order of $80 \mathrm{kV}$. In this paper we show that vigorous reverse convection in the summer hemisphere, with an estimated dusk-to-dawn potential drop in excess of $100 \mathrm{kV}$, existed simultaneously with near-ground state conditions in the winter hemispheres under near-solstice, northward IMF conditions.

Maezawa [1976] first presented evidence that reverse convection cells in the polar cap, with a dusk-to-dawn potential drop, existed during northward IMF. During northward IMF, separate convection cells equatorward of the polar caps, apparently associated with viscous driving, can often be identified [e.g., Burke et al., 1979; Potemra et al., 1984]. Viscouslike convection refers to antisunward flow on closed geomagnetic field lines on the dawn and dusk flanks of the magnetopause. Merging can also occur when the IMF is more nearly east-west, although the merging sites on the magnetopause for this configuration are not yet well understood.

The patterns produced by Potemra et al. [1984] for the northern hemisphere show two reverse convection cells at high latitudes flanked by lower-latitude cells with an opposing sense of convection. Their diagrams for the northern hemisphere show that as $B_{y}$ becomes more negative, the positive, high-latitude cell grows at the expense of the negative cell until the positive cell becomes the dominant polar cap cell. In the southern hemisphere it is the negative cell that dominates as $B_{y}$ becomes increasingly negative. There remains some confusion regarding the way in which one cell becomes dominant over the other. There are two possibilities: (1) One cell grows in area, becoming round, while the other decreases in area, becoming crescent shaped, but the cells have equal potential drops across them, or (2) the potential in one cell grows while the other decreases. This distinction is important because which process occurs indicates whether the cells are merging cells or lobe cells, respectively. Crooker [1988] argues that in merging cells, only process 1 occurs. Lobe cells have no such constraints.

In contrast to the Potemra et al. [1984] patterns, Heppner and Maynard [1987] show distorted two-cell convection patterns for all northward IMF configurations. Part of the distortion produces a wrapping of an extended cell across noon. The degree of distortion depends on the strength of 
$B_{y}$. Their model's regions of sunward flow arise between the distorted cells in the polar cap. The morning cell is generally confined to a region between approximately 0200 and 0600 MLT. To date, the differences between the Potemra et al. and Heppner and Maynard models remain largely unexplained, although Zhu and Kan [1990] argue that a four-cell convection pattern can be changed into a distorted two-cell pattern by nonuniform, anisotropic conductance in the ionosphere. Knipp et al. [1991] used AMIE results and Crooker's [1988] antiparallel merging model to illustrate how severe distortion of a reverse convection pattern could ultimately produce a normal two-cell convection pattern under slowly changing IMF. The time interval involved in changing the configuration was long enough to make the distorted two-cell pattern nearly steady state.

Friis-Christensen et al. [1985] have also derived an empirical model of convection during northward IMF from 20min averages of magnetometer data from the west coast of Greenland during the northern hemisphere summer. Their model shows a $B_{y}$ dependence that is similar to the Heppner and Maynard model but with less severe distortions. The flow is generally antisunward across the polar cap for all IMF orientations.

The impact of a significant $B_{y}$ component in the presence of northward IMF has been discussed by numerous investigators. The IMF $B_{y}$ component produces antisymmetric convection between the northern and southern polar caps, known as the Svalgaard-Mansurov effect [Svalgaard, 1968; Mansurov, 1969]. Recently, Cannon et al. [1991] and Crowley et al. [1992] have used digital ionosonde (digisonde) data from the central polar cap to provide statistical information on the $\mathrm{B}_{\mathrm{y}}$ influence in highest latitudes. McCormac et al. [1991] have presented data from a thermospheric wind analysis that show that $B_{y}$ influences can be traced into the neutral atmosphere. They suggested that the ratio of $\left|B_{y} / B_{z}\right|$ is crucial for determining the existence of reverse convection and that reversed convection only occurs for $B_{z}>0$, $\left|\mathrm{B}_{\mathbf{y}} / \mathrm{B}_{\mathbf{z}}\right|<1$.

Cowley [1981] suggests that the IMF- $B_{x}$ interactions with the geomagnetic field are more subtle than those associated with the other components. In the context of northward IMF, Luhmann et al. [1984], Reiff and Luhmann [1986], Jankowska et al. [1990], and Crooker [1992] have discussed how the IMF $B_{x}$ component can produce interhemispherical differences in convection through preferential merging of the IMF with one ail lobe.

Several studies have shown that convection is much less ordered in the winter polar cap than in the summer polar cap for northward IMF [Burke et al., 1979; Heelis and Hanson, 1980; Bythrow et al., 1985; Hoffman et al., 1988; Carlson et al., 1988]. Whether reduced wintertime conductivity or asymmetric merging is responsible for interhemispheric differences is a point of contention. Zanetti et al. [1982] presented observations during northward IMF when the summer hemisphere, tilted toward the direction of the oncoming solar wind, showed strong Birkeland current activity, while the winter polar cap appeared to have virtually no linkage with the solar wind. However, for the same period, Reiff [1982] demonstrated the existence of sunward convection in the winter polar cap and ascribed the difference in current to the interhemispheric conductivity difference. Crooker [1992] proposes that lobe merging between the IMF and open tail lobe field lines is possible in only one hemisphere for north- ward IMF when either dipole tilt or IMF $B_{x}$ causes lobe field lines from one hemisphere to drape over the dayside volume of closed field lines. The model also suggests that reverse convection is possible only when lobe field lines drape over the dayside magnetopause.

Most previous observational studies of global ionospheric convection have relied either on information from individual satellite passes across the polar regions, which measure electric or magnetic fields only along the track, or on statistical analyses of large collections of ground-based or satellitebased measurements. Individual satellite passes have been able to measure only a small portion of the convection pattern. Statistical analyses may average out or miss smallscale and intermediate-scale features that are important in explaining the drivers of the convection. It is only with the advent of magnetogram inversion techniques [e.g., Mishin et al., 1979; Kamide et al., 1981; Kamide and Buamjohann, 1985], inversion techniques for satellite auroral image data [Marklund et al., 1987], and the extension of these techniques to include electric field and other measurements [Richmond and Kamide, 1988] that it has become possible to study "snapshots" of the convection over the entire polar region [e.g., Kamide et al., 1986; Richmond et al., 1988, 1990; Knipp et al., 1989, 1991; Ahn et al., 1989; Mishin, 1990, 1991; Emery et al., 1990; Marklund et al., 1991; Marklund and Blomberg, 1991]. Our analysis of the events of January 14,1988 , is the first in which we have included satellite electric field measurements in AMIE fits, and it is the first time we have attempted to determine the convection and currents in the southern polar region.

\section{Procedure}

The AMIE procedure and its development have been described by Richmond and Kamide [1988] and Richmond [1992]. It provides an objective method to estimate the high-latitude ionospheric conductivities, electric fields and currents, and associated phenomena from a combination of ground-based and satellite-based instruments, taking into account a priori information about features of the electrodynamics, such as average patterns, expected variability, and spatial correlation distances of electric fields. Each observation is weighted by the inverse square of its effective error, and the uncertainty in the estimated convection electric field is calculated at every point over the polar region. In the present case the uncertainties are substantial, owing to the limited distribution of observation sites in the southern hemisphere and to the limited ability of magnetometer data to help determine the convection in the dark winter northern hemisphere, where the conductivity is often low.

Several upgrades to the AMIE procedure have been made since the above-cited publications. The spatial resolution has been increased by adding more basis functions, up to 244 from the previously used 121 . The additional basis functions have shorter effective wavelengths, down to about $5^{\circ}$ in the north-south direction, signifying effective distance scales down to $5^{\circ} /(2 \pi)$ or roughly $1^{\circ}$. In longitude the minimum wavelength is $30^{\circ}$, corresponding to a distance scale of about $5^{\circ}$ at auroral latitudes. The functions are constructed so as to be capable of representing any general pattern of electric potential poleward of $50^{\circ}$ (previously $56^{\circ}$ ) magnetic latitude.

Analysis of the spatial variability of the electric fields, based on satellite observations in a manner to be docu- 
mented in a future publication, has also permitted us to improve the specification of the matrix $\mathrm{C}_{\mathrm{u}}$ (defined by Richmond and Kamide [1988]), which represents the tatistical properties of this variability. This change affects the manner in which AMIE interpolates and extrapolates from the observations to estimate the continuous convection distribution and also affects the calculation of the uncertainty in the results. In addition, we now compare the mean square differences between computed fields and observations with what the error analysis of AMIE predicts for these differences, and when necessary we adjust the effective data errors to improve the agreement in this comparison. This adjustment increases the objectivity of the data error specifications, which are a necessary input to the AMIE procedure.

The energy flux and mean energy of auroral particles are closely related to the height-integrated ionospheric Pedersen and Hall conductivities, which are calculated as part of the AMIE procedure. We have newly added to the AMIE procedure an explicit estimation of the distributions of auroral energy flux and mean particle energy, based on the direct and indirect observations that are available. Our initial estimates of the energy flux are from the models of Fuller-Rowell and Evans [1987], parameterized by the 10level hemispheric power index. The empirical mean energy model is obtained from the Hall-to-Pedersen ratio of the Fuller-Rowell and Evans [1987] auroral conductance models, by finding a Maxwellian flux that produces the same ratio. The resultant fits in energy flux and mean energy are then converted to conductance. This procedure will be described in greater detail in a forthcoming publication. Usually, we assume that the auroral oval is conjugate, but in this study which is characterized by great interhemispheric diversity, the hemispheres were solved separately for auroral parameters with no assumption of conjugacy.

We have used the Foster et al. [1986] statistical patterns as a priori information. Knipp et al. [1993] found that when data coverage is adequate, the a priori patterns have little influence on the mapped convection results. That study, which also focused on January 14, 1988, showed that the data coverage was adequate in the northern hemisphere. For the southern hemisphere we have found the data coverage adequate to limit the influence of the a priori patterns while $B_{2}$ was northward and the convection was confined to high latitudes.

\section{DATA}

\subsection{Data Locations}

Figure 1 shows the locations of ground-based and satellite-based observations at 0000 UT used in this study for the high-latitude portions of the northern and southern hemispheres. Figures $1 a$ and $1 d$ show the location of 100 magnetometers which are designated by their international three-letter codes. Twelve additional magnetometer stations located between $\pm 40^{\circ}$ magnetic were also used in the analysis. For each radar (Figures $1 b$ and $1 e$ ), both the radar location (large character) and the potential observing locations (small characters) are indicated. At any one time, only a portion or sometimes none of the potential radar-observing locations actually return an echo of sufficient strength to allow measurement of the convection. In general, the AMIE procedure uses data from a single averaging period or scan for each radar, which varies between 5 and $20 \mathrm{~min}$ for this analysis. In Figures $1 a-1 c$ the northern hemisphere is viewed from above the north pole. In order to keep the same display format in magnetic latitude and magnetic local time for the two hemispheres the southern hemisphere ionosphere (Figures $1 d-1 f$ ) is viewed as though one were looking at it through the Earth.

Both the DMSP F7 and F8 satellites are in Sunsynchronous orbits at an altitude of around $840 \mathrm{~km}$ and have orbital periods of around $100 \mathrm{~min}$. The equatorial crossings of F7 are close to 0900 and $2100 \mathrm{LT}$, while those of F8 are about 0600 and 1800 LT. As the Earth rotates underneath the satellite orbital tracks, the footprints of the tracks move in magnetic latitude/magnetic local time coordinates because of the offsets of the magnetic poles from the geographic poles. Figures $1 c$ and $1 f$ show the extreme excursions of the satellite tracks in magnetic coordinates throughout the universal time of day for the northern and southern hemispheres, respectively.

\subsection{DMSP Satellite Data}

Both DMSP F7 and F8 measured the downward energy flux and mean energy of precipitating auroral electrons, which are used for estimating auroral conductivities. DMSP F7 also measured the vector magnetic field [Rich and Gussenhoven, 1987], while F8 measured the cross-track component of ion drift with the ion drift meter (IDM) [Heelis and Hairston, 1990]. The horizontal components of the magnetic field, after subtraction of a main geomagnetic field model, are sequentially differenced to provide the gradient, along the satellite track, of the magnetic field perturbation for use in AMIE, as in the works of Knipp [1989] and Emery et al. [1990]. The ion drifts are mapped along geomagnetic field lines, scaled to a reference altitude of $110 \mathrm{~km}$ and converted into electric fields by the approximate formula:

$$
\left.\mathbf{E}_{110 \mathrm{~km}}=-\mathbf{v}(\mathrm{h}) \times \mathbf{B}_{110 \mathrm{~km}}\left[\mathrm{R}_{\mathrm{E}}+110 \mathrm{~km}\right) /\left(R_{E}+\mathrm{h}\right)\right]^{3 / 2}
$$

Since only the velocity perpendicular to the satellite track is measured, only the electric field component along the track is obtainable. All DMSP data for each hemisphere within $\pm 15 \mathrm{~min}$ of an analyzed time are used.

\subsection{Incoherent Scatter Radars}

The Sondrestrom incoherent scatter radar ("S" in Figure 16 ) provided latitude scans of the vector plasma drift every $20 \mathrm{~min}$ throughout the period as well as conductance measurements above the radar. The plasma drift values are converted to electric fields by (1). All observations within $10 \mathrm{~min}$ of the time being analyzed by AMIE are utilized. The Tromso receiver of the EISCAT system (" $E$ " in Figure 1b) alternated between two low-elevation look directions $24^{\circ}$ apart on either side of the magnetic meridian every $5 \mathrm{~min}$. The line-of-sight velocities are converted to electric fields by (1). The Millstone Hill incoherent scatter radar ("M" in Figure 1b) scanned over $40^{\circ}$ of azimuth from north-northwest to northeast at a low-elevation angle every $5 \mathrm{~min}$.

\subsection{HF Sounders}

The Polar Anglo-American Conjugate Experiment (PACE) consists of two coherent, high-frequency, backscatter radars [Greenwald et al., 1985; Baker et al., 1989] operating on a fixed frequency between 8 and $20 \mathrm{MHz}$ deployed at Goose Bay ("G" in Figure 1b) and Halley ("H" in Figure 

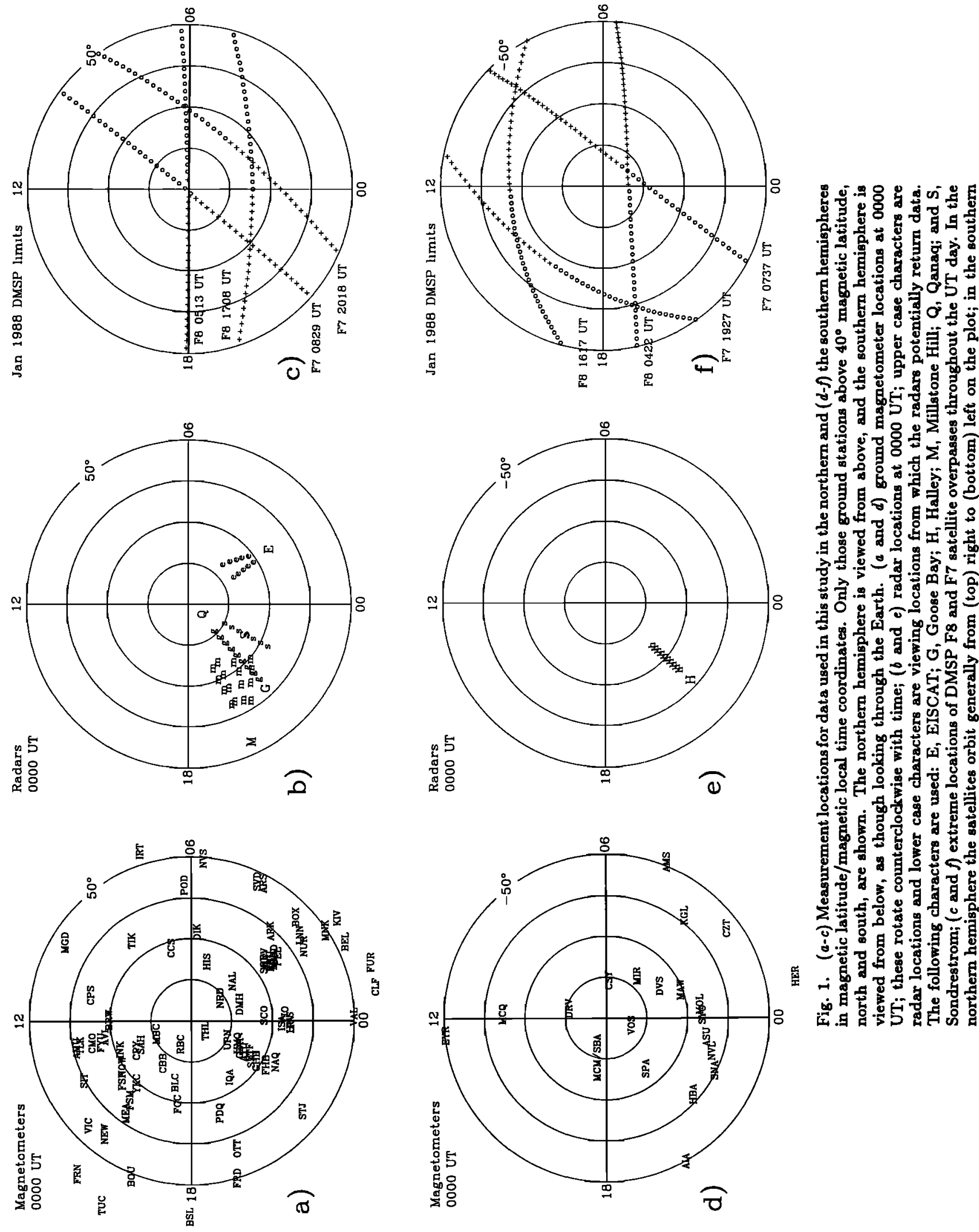

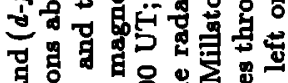

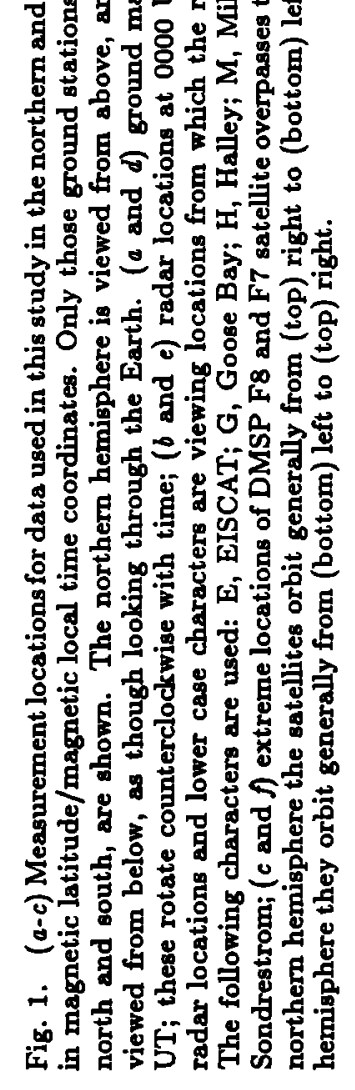


1e). The radars require the presence of decameter scale ionospheric irregularities. These drift with the ambient plasma at $F$ region altitudes [Ruohoniemi et al., 1987]. The drift values are converted to electric fields by (1). Ten-min averages are used from Goose Bay, while 5-min averages are used from Halley.

\subsection{Digisonde}

The Qanaq, Greenland, digital ionosonde (digisonde, " $Q$ " in Figure 1b), yields plasma drift velocities from the $F$ region [Reinisch, 1986; Buchau et al., 1988]. Digisonde convection analyses have been presented by Reinisch et al. [1989], Cannor et al. [1991], and Crowley et al. [1992]. Drift velocities were provided every $15 \mathrm{~min}$ and are converted to electric fields by (1).

\subsection{Ground Magnetometer Data}

The magnetometer locations above $40^{\circ}$ north and south magnetic latitude are shown in Figures $1 a$ and $1 d$. The magnetic perturbations used as input for the AMIE procedure are the difference between disturbed day values and quiet day values. The quiet day used for most stations is between January 9, 1988, $1200 \mathrm{UT}$, and January $10,1988,1200 \mathrm{UT}$. The $D_{\text {, }}$ effect is removed from the magnetic $X$ (northward) component of all stations as part of the data processing.

\section{INTERPlanetary and Geophysical Parameters}

Figure 2 shows the geophysical conditions for January 14, 1988. At the top of Figure 2 are the times for which observations from various instruments are available. Data availability is indicated by broken or continuous bars. Figures $2 b, 2 c$, and $2 d$ show the IMF $B_{x}, B_{y}$, and $B_{z}$ components in geocentric solar-magnetospheric (GSM) coordinates, as measured by the IMP 8 satellite which was located at approximately $35 R_{E}$ in the midmorning local time sector. The total field strength, $B_{1}$, (shown in Figure $2 e$ ) was unusually large throughout most of January 14, reaching $30 \mathrm{nT}$ at around $1600 \mathrm{UT}$ on January 14 . The changes in field direction were generally slow, associated with the organized and unusually strong magnetic field within an interplanetary magnetic cloud [Forrugia et al., 1993a]. It is the slow, smooth execution of a large rotation $\left(>180^{\circ}\right)$ over the scale of a day with a minimum of high-frequency fluctuations that defines a magnetic cloud [Burlaga et al., 1990] and allows us to extract a wealth of information on variations of solar-wind-magnetospheric-ionosphere coupling processes. The ratio of IMF $B_{y}$ to $B_{z}\left(\left|B_{y} / B_{z}\right|\right)$ is shown in Figure 2f, where it is maximized at a value of one. Figure $2 g$ shows the solar wind speed, which was relatively large for most of January 14. The high speed is associated with spacecraft-to-magnetopause transit time of less than $5 \mathrm{~min}$.

The geophysical response had a clear association with the IMF direction. Figure $2 h$ shows the AE index, calculated from the 60 magnetometer stations of our set that lie between magnetic latitudes of $55^{\circ}$ and $76^{\circ}$ north or south. (As noted by Akasofu et al. [1983] and Kamide and Akasofu [1983], auroral electrojet indices calculated from more than the conventional 12 northern hemisphere sites will be larger than the conventional indices.) The index showed moderate activity until about $0530 \mathrm{UT}$ and then a subsequent reduction in activity as the IMF became strongly northward. Electrojet activity increased after 1200 UT as the IMF $B_{y}$ (o) JANUARY 14, 1988

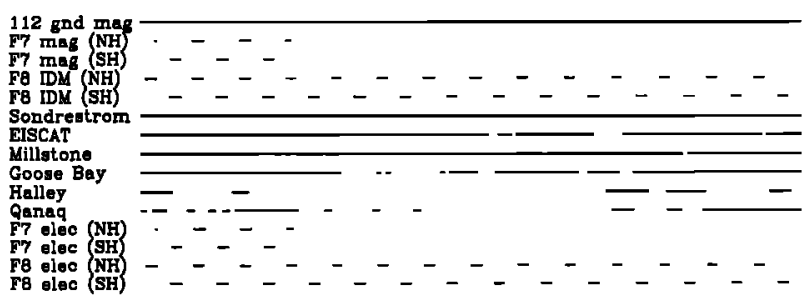

(b)

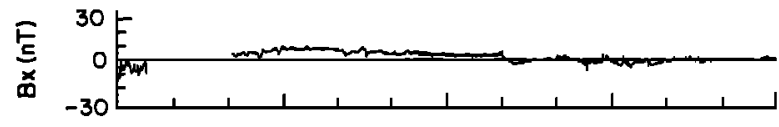

(c)

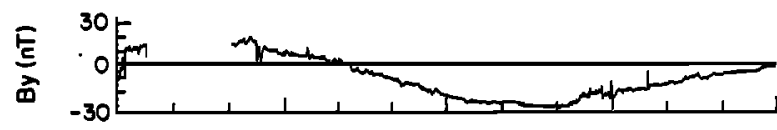

(d)

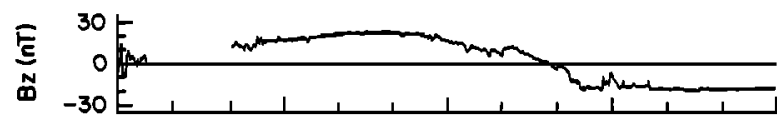

(e)

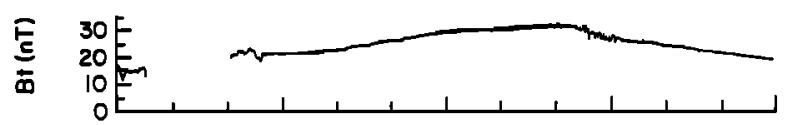

(f)

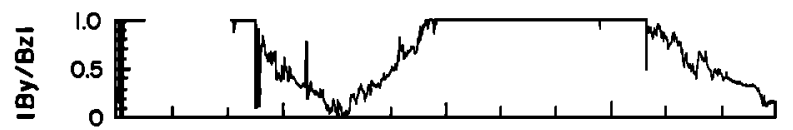

(g)

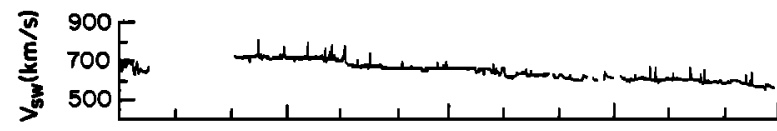

(h)

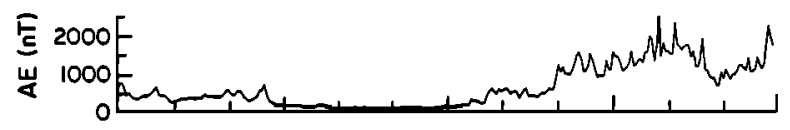

(i)

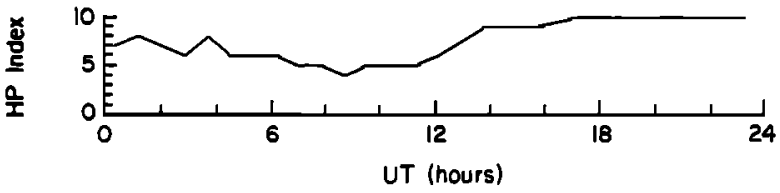

Fig. 2. Data availability and geophysical conditions on January 14, 1988. (a) Times for which data are available. The line next to each instrument or set of instruments is filled when data are available and is blank when data are missing. The instruments are 112 ground magnetometers; DMSP F7 magnetometer in the northern hemisphere; DMSP F7 magnetometer in the southern hemisphere; DMSP F8 ion drift meter (IDM) in the northern hemisphere; DMSP F8 IDM in the southern hemisphere; Sondrestrom incoherent scatter radar; EISCAT incoherent scatter radar; Millotone Hill incoherent scatter radar; Goose Bay HF radar; Halley HF radar; Qanaq digisonde; DMSP F7 auroral electron spectrometer in the northern hemisphere; DMSP F7 auroral electron opectrometer in the southern hemisphere; DMSP F8 apectrometer in the northern hemisphere; and DMSP F8 auroral electron spectrometer in the southern hemisphere. (b-e) Interplanetary magnetic field (IMF) data from the IMP 8 satellite of $B_{x}, B_{y}, B_{z}$, and $B_{t}$, respectively, in geocentric solar-magnetospheric coordnates. $(f)$ The derived ratio $\left|B_{\mathbf{y}} / \mathrm{B}_{\mathbf{z}}\right|$. (g) The solar wind velocity measured by the IMP 8 satellite. $(h)$ The $A E$ index, calculated from 49 northern and 11 outhern hemisphere stations located between $55^{\circ}$ and $76^{\circ}$ magnetic. (i) The hemispheric power index, defined by Foster et al. [1986] and calculated from auroral particle precipitation measurements on the DMSP spacecraft.

component became large, even though $B_{\mathbf{z}}$ was still positive. Shortly after 1600 UT the IMF turned strongly southward and the $A E$ index jumped above $600 \mathrm{nT}$, where it remained for nearly 19 hours. 
Figure 2i shows the hemispheric power index (as defined by Foster et al. [1986]), determined from measurements by Defense Meteorological Satellite Program (DMSP) instruments of auroral particle precipitation energy $f$ lux in the range $300 \mathrm{eV}$ to $20 \mathrm{keV}$. Moderate precipitation levels were measured before 1300 UT on January 14, but during the ensuing storm, the levels increased. The hemispheric power index is the parameter used to specify the initial models of the electric potential and the auroral energy flux and mean energy of the AMIE procedure in the present study.

\section{REsUlts aND Discussion}

\subsection{IMF Regime: $B_{x}>0, B_{y}>0, B_{z}>0$}

Figures $3 a$ and $4 a, 4 b$ and $4 c$ show the convection at 0255 UT, $0345 \mathrm{UT}$, and $0435 \mathrm{UT}$. Available ground magnetometer data, radar data, and ion drift meter (IDM) data are overlain on these plots. Satellite magnetometer observations are available and assimilated but not shown. According to Freeman et al. [1993] the Earth was immersed in the sheath region between the interplanetary shock and the magnetic cloud proper prior to 0500 UT. Because of an IMP 8 data gap between $0115 \mathrm{UT}$ and $0400 \mathrm{UT}$ we cannot be sure of the IMF orientation for the $0255 \mathrm{UT}$ and $0345 \mathrm{UT}$ plots, but continuity of the main convection features in the plots and interpolation of the IMF data suggest that the IMF conditions were similar for all of the convection patterns in Figures 3 and 4 , that is, $B_{x}>0, B_{y}>0, B_{z}>0$.

Figure $3 b$ [after Cumnock et al., 1992] displays the singlecomponent, high-resolution IDM data for $0255 \mathrm{UT}$, showing very ordered flow with speeds below $1 \mathrm{~km} / \mathrm{s}$. The large-scale pattern in Figure $3 a$ was dominated by a round positivepotential convection cell, with the latitudinal extent of the cell defined by the IDM data and the strength of the cell determined both from the IDM data and the ground magnetometer data. More than $50 \mathrm{kV}$ of the $85 \mathrm{kV}$ cross-polarcap potential difference was contained in this cell, which was centered near $83^{\circ}$ magnetic latitude. The remainder of the potential was associated with an elongated negative cell in the dusk region.

We interpret this pattern in the framework of merging, lobe, and viscous convection as modulated by an IMF configuration with all components positive. Figure $3 c$ from $B$ urch et al. [1985], which was originally drawn for strong $B_{y}$ and southward IMF conditions, provides a conceptual diagram of how lobe, merging, and viscous cells may combine to form a large-scale convection system. Based on suggestions by Reiff and Luhmann [1986] and our results, we have applied this diagram to northward IMF, as do Burke et al. [1993]. The merging convection (drawn as a heavy contour) provides an outer convective envelope in which both viscous cells (dashed regions) and lobe cells (light contours) can be embedded. The merging and viscous cells share the same sense of convection, and in the absence of interhemispheric conductivity differences and $B_{y}$ effects should be conjugate. Merging convection is in the usual sense: antisunward across the polar cap and sunward at lower latitudes. The lobe cell circulation is completed at high latitudes and may oppose the convection associated with closely positioned viscous cells. Lobe circulation is inherently nonconjugate.

The arrow in the high-resolution data plot (Figure $3 b$ ) points to a region of diminished sunward flow which has been averaged out of the data shown in Figure $3 a$. The Cum- nock et al. [1992] detailed analysis of the convection during the early hours of January 14, 1988, suggests that the diminished flow region may be the signature of an embedded viscous cell. In general, viscous cells may not be resolvable in our large-scale mappings of ionospheric convection. Co. ley et al. [1987] estimate a typical ionospheric width of 50 $\mathrm{km}$ for these cells and suggest that the signature of a viscous cell may be smeared out by field-aligned potential drops and could show up as either a small region of antisunward flow or a region of diminished sunward flow. Mozer [1984] found on average only 2 to $3 \mathrm{kV}$ of potential associated with them. G. Lu and P. H. Reiff (unpublished manuscript, 1992) argue that ground magnetometers cannot sense the magnetic deviations associated with such small-scale features. When the IDM data are assimilated they are averaged into $20-\mathrm{s}$ bins which correspond to a resolution of $150 \mathrm{~km}$ and are thus unlikely to sense viscous cells of normal size.

In accord with Burch et al. [1985] we identify any convection circulation that completely closes poleward of the viscous cell as lobe convection. We propose that lobe, merging, and viscous drivers combined to produce the convection pattern in the southern hemisphere at $0255 \mathrm{UT}$. The dusk cell is probably the result of both merging and viscous effects, while the dawn cell is likely to be the result of all three convection drivers. $B_{y}$ comparing Figures $3 a$ and $3 c$ and using the above criteria to identify lobe convection, it appears that lobe convection contributes to an imbalance of the two potential cells [Crooker, 1979; Burch et al., 1985; Reiff and Burch, 1985] and accounts for approximately $30 \mathrm{kV}(35 \%)$ of the potential drop across the polar region at $0255 \mathrm{UT}$. Reiff and Luhmann [1986] attribute voltages as high as 35 $\mathrm{kV}$ to the lobe circulation process.

Figures $4 a$ and $4 b$ show the 0345 UT southern and northern hemisphere convection patterns, respectively. The southern hemisphere convection plot for $0435 \mathrm{UT}$ is shown in Figure 4c. At 0345 UT the DMSP satellite was over the northern pole. Hence the southern hemisphere convection pattern was mapped from only Halley Bay HF data and ground magnetometer data. The Halley Bay observations help confirm the continued existence of the large-scale convection around the positive potential cell, while the magnetometer data, which provide the bulk of the information, give definition to the rest of the convection cell. Again more than $50 \mathrm{kV}$ of the potential drop across the polar cap was associated with the positive cell. The nature and extent of the negative cell at $0345 \mathrm{UT}$ is much less certain (as indicated by the dashed contour lines) than at $0255 \mathrm{UT}$, primarily due to the unavailability of data. The negative cell bears an interesting resemblance to the distorted cell drawn by Heppner and Maynard [1987] for similar IMF conditions. However, the stretching of this cell may be only an artifact of the way the AMIE procedure extrapolates the potential beyond the region of observations. Thus it is possible that the AMIE procedure has linked two physically unrelated regions of negative potential. We suspect this to be the case because two spatially distinct cells are mapped for subsequent times (see Figures $5 d, 5 e$, and $5 f$ ).

The northern hemisphere pattern for 0345 UT (Figure $4 b$ ) shows a weak, but spatially broad negative potential cell dominating the afternoon region and a smaller positive cell in the morning region. In stark contrast to the vigorous but ordered convection mapped for the southern hemisphere at $0345 \mathrm{UT}$, the northern hemisphere convection is weaker 

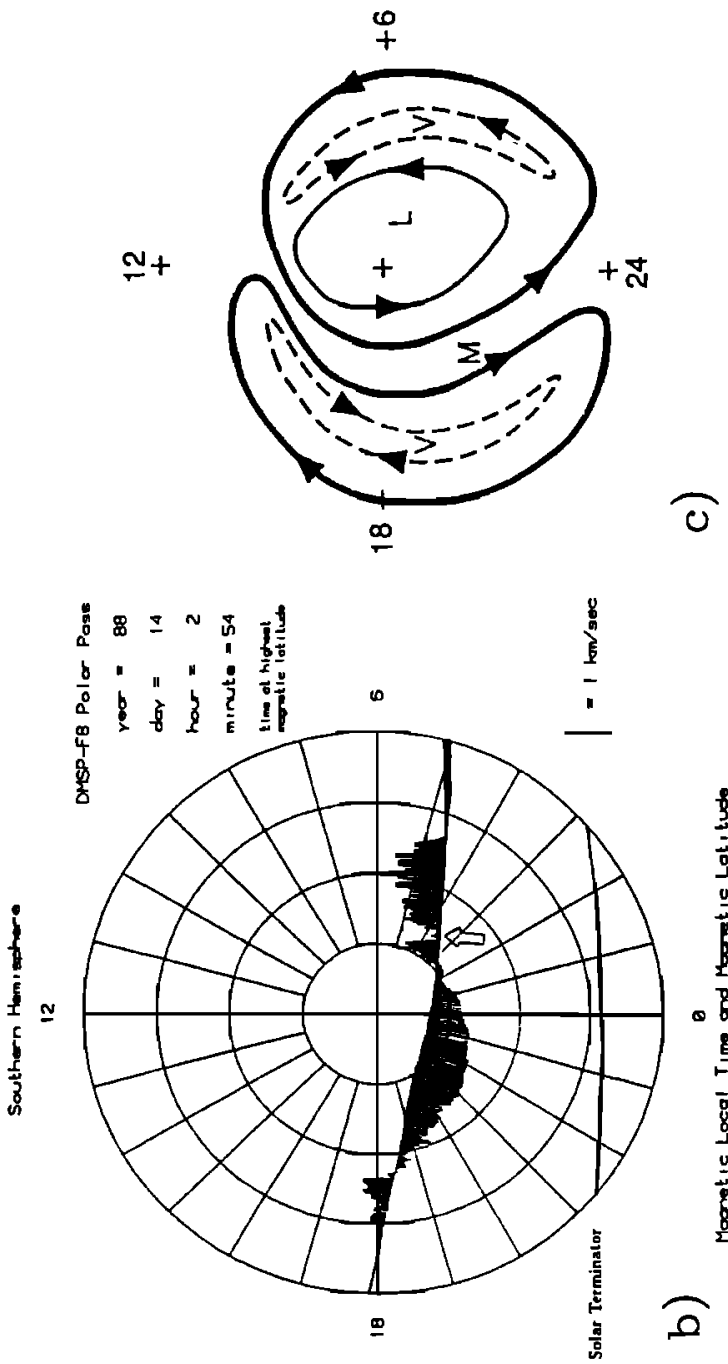

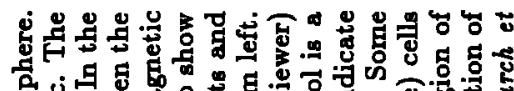

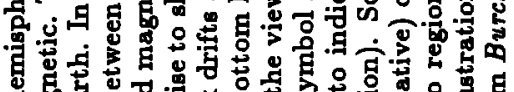

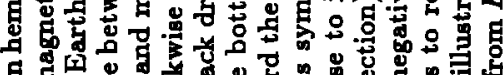

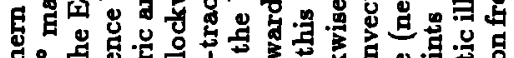

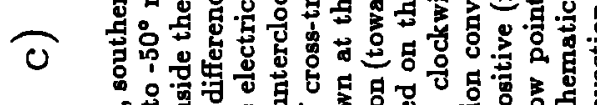

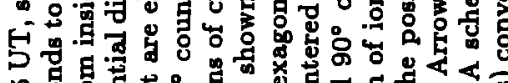

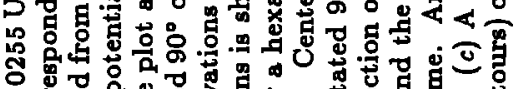

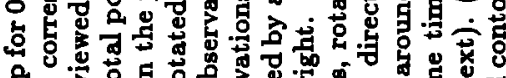

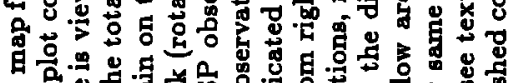

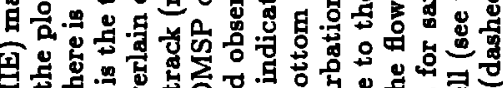

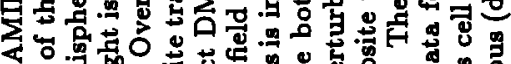

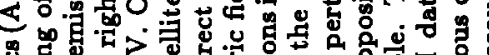

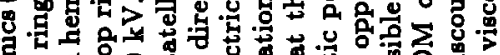

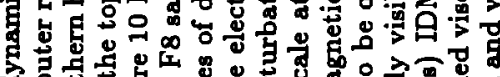

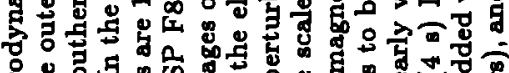

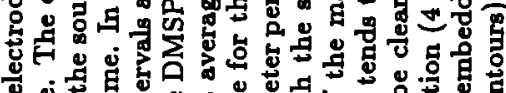

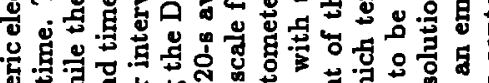

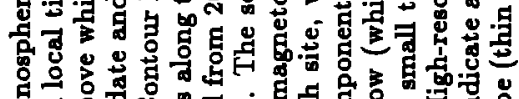

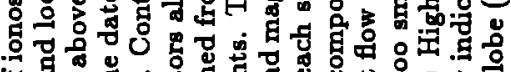

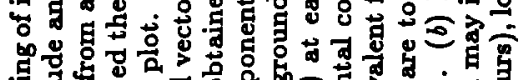

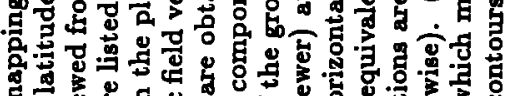

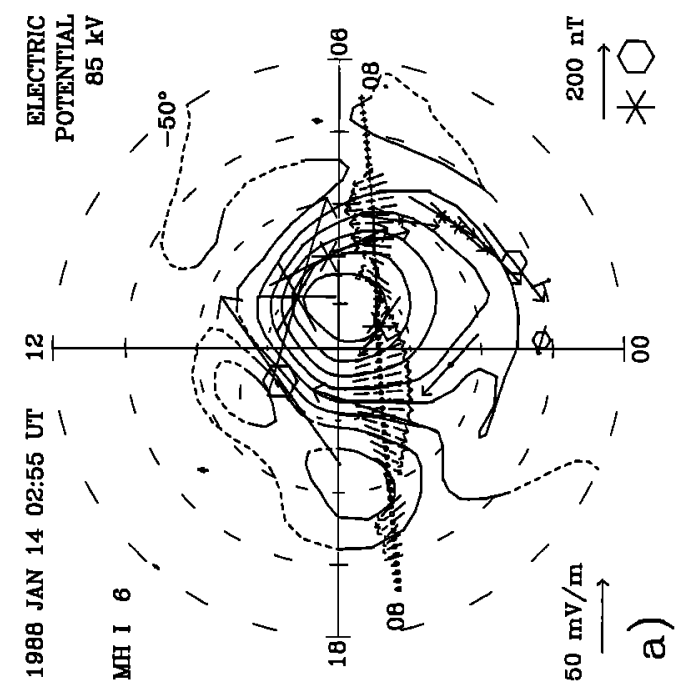

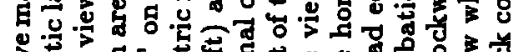

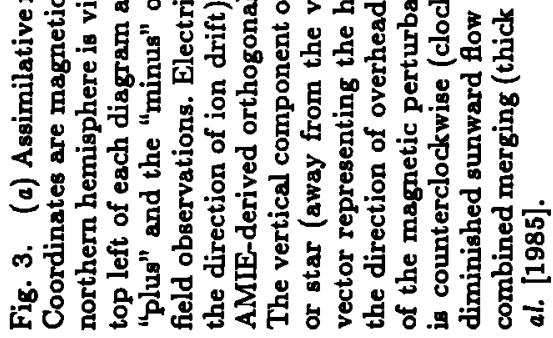



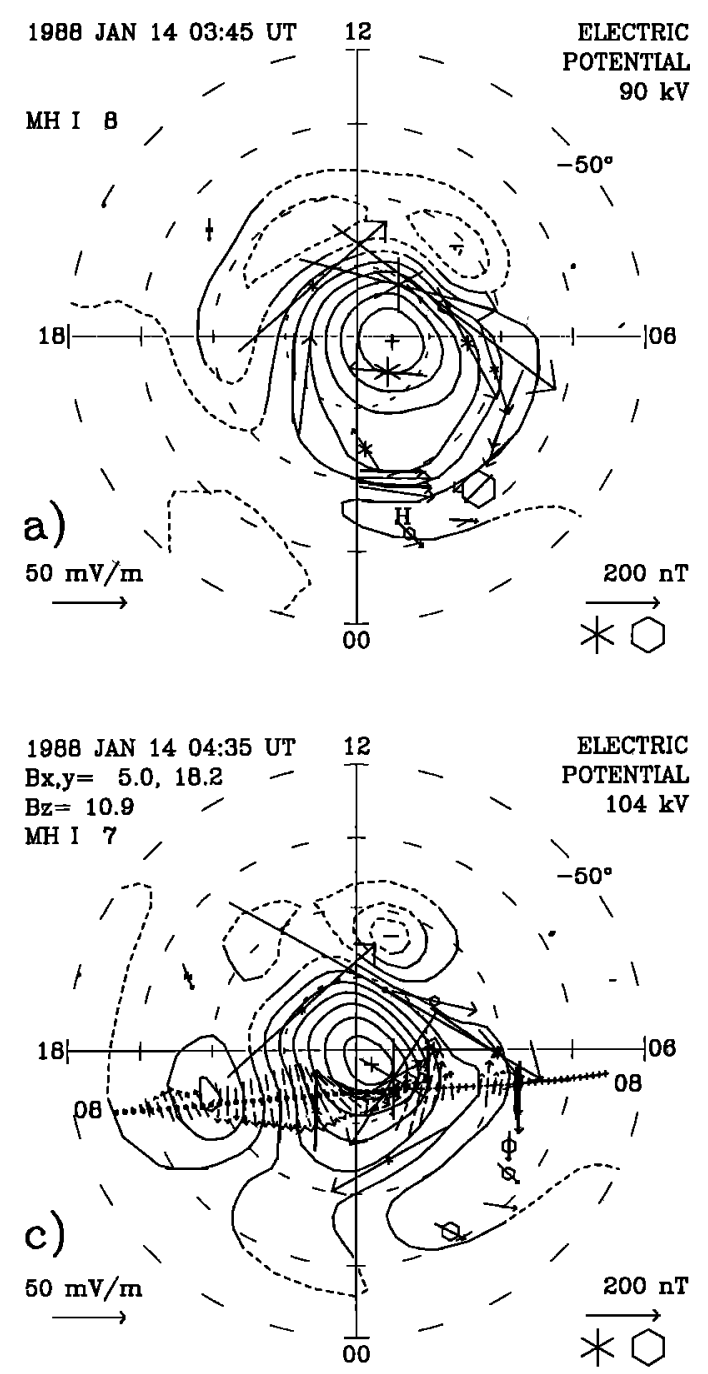

and highly turbulent. Numerous flow reversals exist in the northern hemisphere IDM data, and regions of high-speed flow are interspersed with regions of near-zero flow velocity. This type of flow is typical of the winter hemisphere. Burke et al. [1979] and Hoffmon et al. [1988] estimate that largescale coherent flow patterns in satellite data can only be recognized $30 \%-40 \%$ of the time in winter when $B_{2}$ is positive. According to Hoffman et al. [1988] these patterns tend to be weaker, more contracted versions of those observed during active periods. Generally, the clearest patterns emerge from the dayside where conductivities are relatively high. Heelis et al. [1986] point out that these coherent patterns tend to occur during times of extremely large and prolonged northward IMF, compatible with our results.

The weakness of the 0345 UT northern hemisphere convection may be due in part to a large antisunward dipole tilt and the positive $B_{x}$ component. Reiff and Luhmann [1986] suggest that lobe cell formation should be difficult in the northern hemisphere when $B_{z}>0$, which was probably true for this time, and Crooker [1992] suggests that lobe cells can exist only in the summer hemisphere or the $B_{x}$-favored hemisphere in which the geomagnetic field $B_{x}$ component is antiparallel to the IMF $B_{x}$ component. Therefore we find it likely that most of the cross-polar-cap potential drop $(\sim 50$ $\mathrm{kV}$ ) in the northern hemisphere should be associated with viscous and/or merging cells. This value is in good agree-

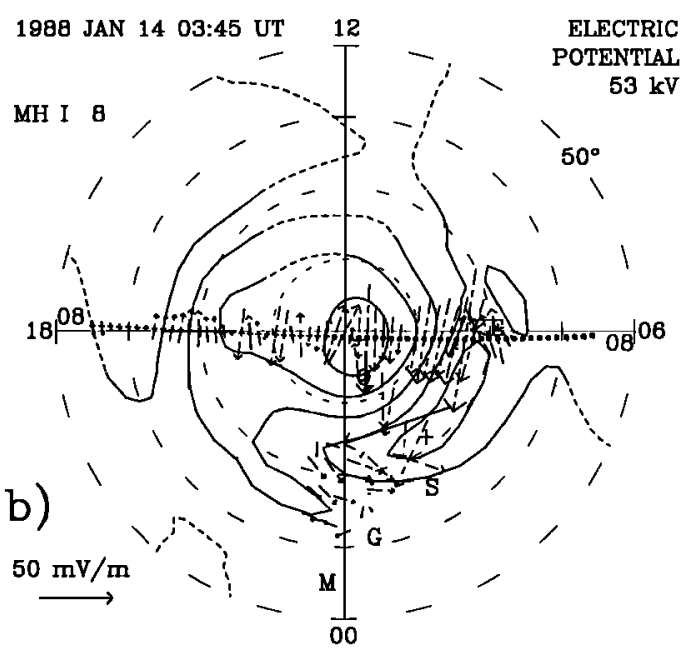

Fig. 4. Electric potential patterns for $B_{x}>0, B_{y}>0, B_{2}>0$ : (a) $0345 \mathrm{UT}$, southern hemisphere; (b) $0345 \mathrm{UT}$, northern hemiophere; and (c) 0435 UT, southern hemisphere. Five-minute averages for IMF $B_{x}, B_{y}$, and $B_{z}$ are shown in (c) in the top left. In (b) electric fields measured by the Goose Bay, Millstone Hill, and EISCAT radars are poleward of the letters "G", " $M$ ", and "E" (partially obscured by the DMSP data), respectively. The EISCAT and Millstone Hill measurements are line-of-sight velocities, so the resultant electric fields shown include the calculated cross-track drift (or line-of-sight electric field). (Remember that the fields have been rotated $90^{\circ}$ to point in the direction of the ion drift.) There are also Sondrestrom ("S") and Qanaq ("Q") measurements. (a) Halley HF measurements are plotted poleward of the " $\mathrm{H}$ ". Some of the southern hemisphere magnetic perturbations are too small to be clearly visible at the times shown in the figures. (b) For clarity the northern hemisphere ground magnetometers are not shown. ( $a$ and $c$ ) The flow is anti sunward across the polar cap and sunward at lower latitudes. (b) Antisunward flow exists between the positive and negative potential cells; sunward flow exists at latitudes near $70^{\circ}$ magnetic. See Figure $3 a$ for further details.

ment with the merging/viscous voltage value we suggested for $0255 \mathrm{UT}$ in the southern hemisphere. Since merging and viscous interactions should be similar between hemispheres, we would expect relatively good agreement in these values. The impact of the large, positive $B_{y}$ component is seen in the enhancement of the southern (northern) hemisphere dawn (dusk) cell at $0345 \mathrm{UT}$.

The southern hemisphere convection at 0435 UT (Figure $4 c$ ) was also dominated by a large positive convection cell which most likely contained embedded lobe circulation. This plot is the first convection plot for which we can verify the IMF values $\left(B_{x}=5.0 n T, B_{y}=18.2 n T, B_{z}=10.9\right.$ nT) which are 5-min averages centered on 0435 UT. The pattern is similar to the southern hemisphere patterns for $0255 \mathrm{UT}$ and $0345 \mathrm{UT}$. However, islands of negative potential are evident in the region previously shown with a single elongated region of negative potential (0345 UT, Figure $4 a$ ). It is possible that these islands simply reflect the influence of individual magnetometers and/or the IDM data in the AMIE estimation procedure. But there may be some addtional significance to the discrete nature of these cells. Cumnock et al. [1992] argue that the region near 1100 MLT is associated with the center of an expanding lobe cell whose development is associated with the growing magnitude of the $\mathrm{B}_{\mathbf{z}}$ component. They suggest a means by which a dominant, single-lobe cell convection configuration evolves into a 

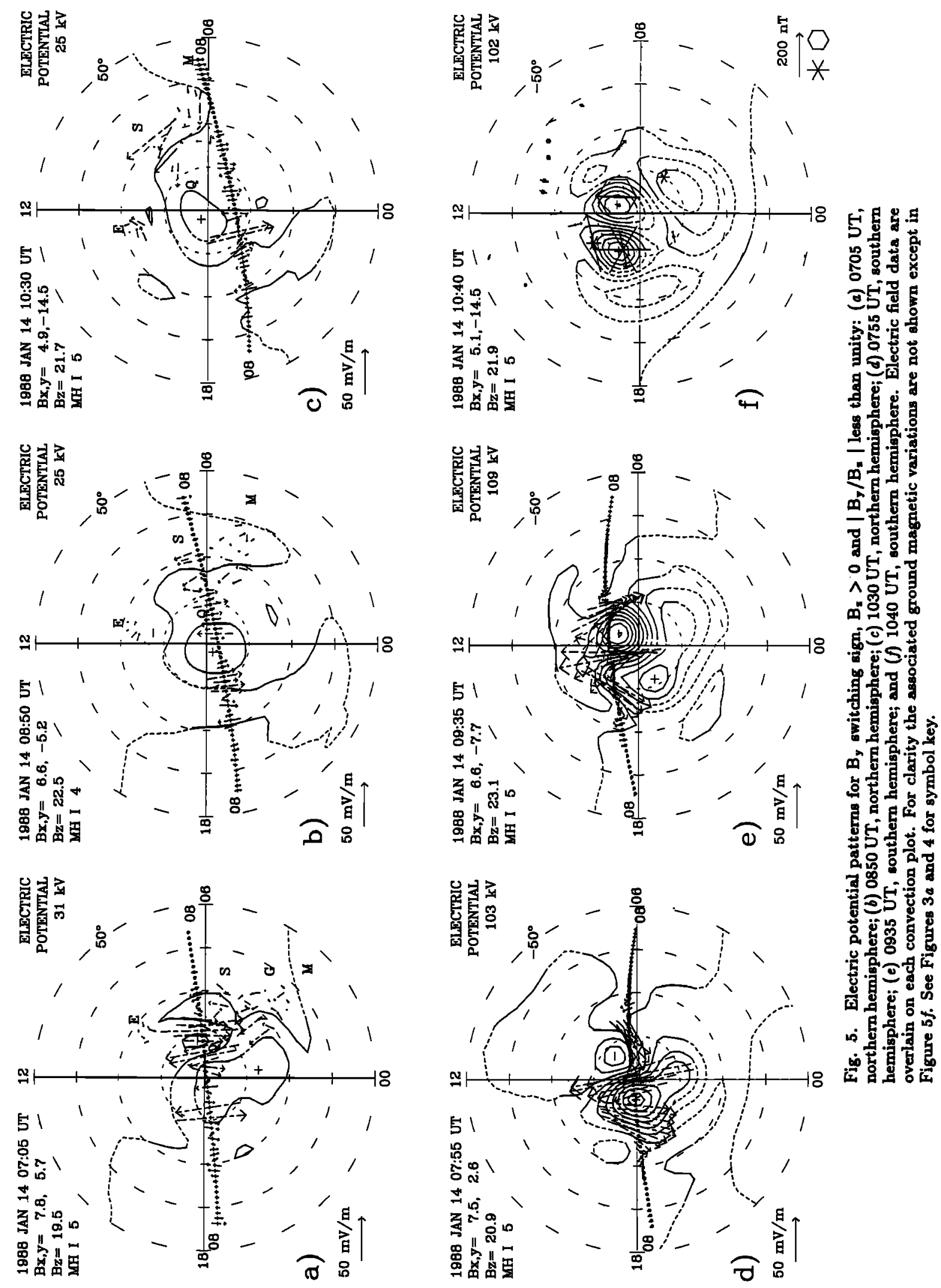
double lobe cell convection configuration. It is possible that the distorted cell stretching across magnetic noon in Figure $4 a$ is actually a combination of viscous and merging convection (dusk region) and $B_{2}$-driven lobe convection (dawn region). At 0435 UT (Figure 4c) and 0755 UT (Figure 5d) these regions become increasingly more distinct.

5.2. IMF Regime: $B_{x}>0, B_{y}$ Switching Sign, $B_{z}>0$, and $\left|B_{y} / B_{z}\right|$ Less Than Unity

The IMF underwent a slow change between $0600 \mathrm{UT}$ and 1130 UT. The $B_{y}$ component slowly decreased while $B_{z}$ remained strongly positive. The solar wind speed remained high. In this interval we witness the development of strong reverse convection in the southern hemisphere. Our data show that a conjugate reverse pattern did not exist in the northern hemisphere. The total potential difference in the northern hemisphere averaged to roughly one third that in the southern hemisphere, and the nature of the convection cells is quite different between the hemispheres. As our previous discussion suggested, the positive $B_{x}$ component and the extremely tilted dipole appear to control the strength of convection in each hemisphere.

We begin the series at 0705 UT (Figure $5 a$ ). The ground magnetometers in the northern hemisphere (not shown) had negligible deviations while, the IDM data (overlain in Figure 5a) show regions of highly structured ion flow. As a result the northern hemisphere convection was highly structured; Figure $5 a$ shows multiple convection reversals. The IMF changed little in the subsequent $50 \mathrm{~min}$, yet the state of convection in the southern hemisphere at 0755 UT (Figure 5d) was very different from that in the north at $0705 \mathrm{UT}$. As reported by Freeman et al. [1993] and shown in Figure $5 d$, the IDM recorded strong, organized flow vectors consistent with a reverse convection pattern at very high latitudes.

At 0850 UT (Figure $5 b$ ) the northern hemisphere convection was in a relaxed state with little organized structure evident in the observations and with only a $25-\mathrm{kV}$ potential drop in the polar region. The $B_{y}$ component had become negative. A single round cell is mapped from the turbulent IDM data. The situation was very similar for 1030 UT
(Figure 5c), although small ground magnetic perturbations (not shown) combined with data from the EISCAT radar ( ${ }^{2} \mathrm{E}$ ' in Figure $5 c$ ) to yield islands of negative potential in the afternoon sector and a $25-\mathrm{kV}$ potential drop across the polar region. During the same period the southern hemisphere convection strengthened. Electric field values in the vicinity of the reverse convection cells at $0935 \mathrm{UT}$ (Figure 5e) were over $100 \mathrm{mV} / \mathrm{m}$, producing in a dusk-to-dawn potential drop of $109 \mathrm{kV}$ with more than $60 \mathrm{kV}$ in the negative potential cell. Sensitivity test runs for $0935 \mathrm{UT}$, with ground magnetometer and satellite data incorporated separately, confirm the large reverse potential drop. The high solar wind velocity may help explain these large electric field values. In showing Figure $5 f$, we deviate slightly from the other plots of the convection series to show the convection for $1040 \mathrm{UT}$ which contained no IDM data (the subsequent DMSP pass, which just barely skims the sunward edge of the reverse convection, is shown in Figure $7 a$ ). We do so to confirm the sensitivity test at $0935 \mathrm{UT}$, which showed approximately the same reverse convection pattern using either ion drift data alone or magnetometer data alone. The two reverse cells are determined by large and oppositely directed $\mathrm{Z}$ variations, as shown in Figure $5 f$. The pattern at $1040 \mathrm{UT}$ also illustrates the persistent difference in convection between the two hemispheres that existed while the magnitude of $B_{y}$ remained less than that of $B_{z}$.

Figure $6 a$ shows schematically a possible magnetic topology that is of assistance in interpreting the interhemispheric differences just described. The figure illustrates the magnetospheric configuration during periods of northward IMF when the Earth's dipole is tilted into the solar wind, appropriate to summer in the southern hemisphere [Crooker, 1992]. The dashed curves lie in the noon-midnight meridian plane, with the dotted-dashed outlining the magnetopause, and the solid curves drape over the dusk flank. At the merging site on the magnetopause (marked by an " $\mathrm{X}$ " in the southern hemisphere) an open lobe field line merges with the northward IMF to form an open field line that drapes over the dayside and subsequently convects tailward generating lobe convection. The topology is similar to that proposed
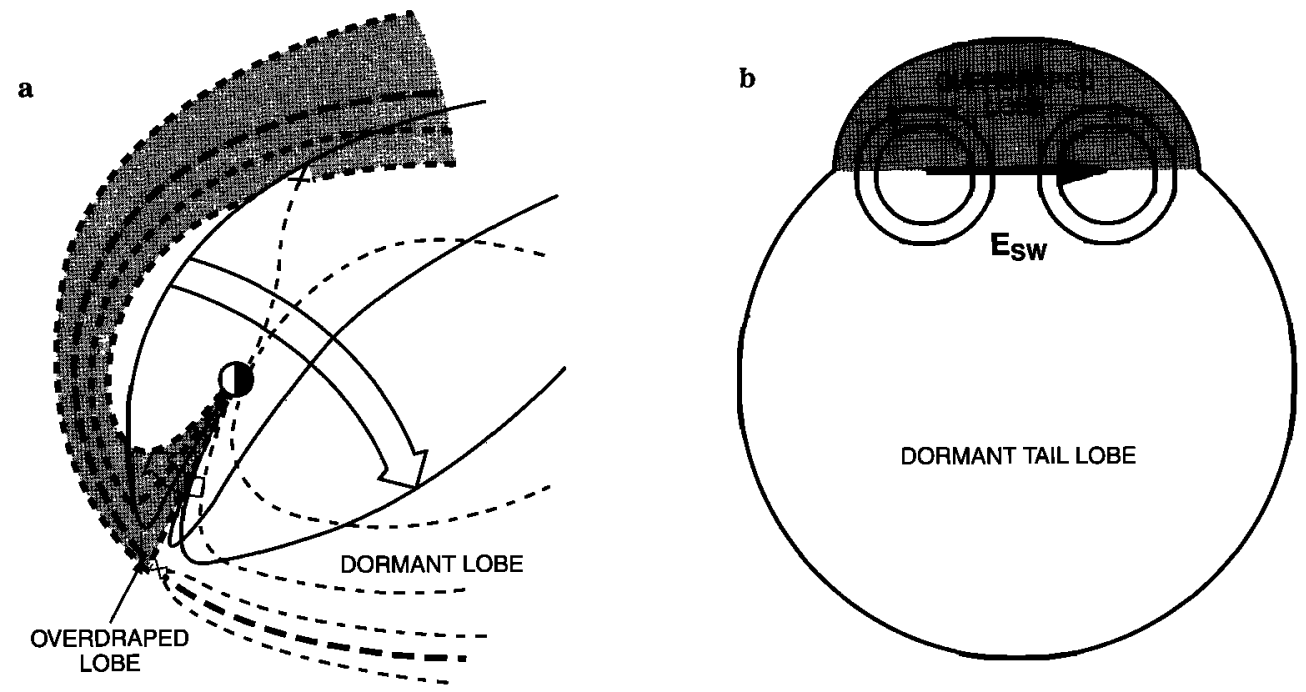

Fig. 6. (a) Schematic illustration of overdraped lobe field lines (shaded) created by lobe merging in the southern hemisphere. A dormant tail region is indicated in the unshaded region tailward of the overdraped dayside. See text for explanation. (b) Mapping of the overdraped and dormant tail lines (shaded area) to the polar cap. 
earlier for the generation of reversed, two-cell convection occurring completely on open lobe field lines during periods of northward IMF [Russell, 1972; Maezawa, 1976] except that much of the overdraped flux lies inside the magnetopause. The resulting overdraped lobe topology suggested here helps alleviate the steady state problem of sunward flow in the ionosphere on field lines connected to antisunward flowing solar wind [Hill, 1992]. The large open arrow in the figure indicates the sense of circulation in the dusk cell. A symmetric dawn cell is assumed to exist on the other side of the noon-midnight meridian plane. The lobe field lines form a funnel of sunward tipped flux that splays out over the surface like hair blowing in the wind.

What is different from the earlier versions [Russell, 1972; Maezawa, 1976] and pertinent to the AMIE results is that the topology allows lobe cells in one hemisphere only, the summer hemisphere, in agreement with the well-ordered convection observed there and the lack of ordered convection in the winter hemisphere (compare Figures $5 a-5 c$ and $5 d-5 f$ ). In the model the flux centers on the magnetic poles. The amount of open flux in the overdraped lobe and, consequently, circulating in the lobe cells is determined by the degree of dipole tilt. Although the diagram shows relatively modest amounts of open flux, extreme dipole tilt and large positive IMF values can substantially increase the circulating flux. These model features are consistent with the nearpole location and small size of the observed reversed cells as mapped in Figures 5d-5f. The proposed lobe cell convection is basically a dayside rather than a tail process, as suggested by the schematic in Crowley et al. [1992], who have used digisonde data from Qanaq, Greenland, to study polar cap convection.

Figure $6 b$ illustrates the lobe convection cells generated in the southern polar cap by the Figure $6 a$ merging topology. The shaded region maps to the overdraped lobe. The electric field from the merging site is applied across the nightside of this region, driving the sunward convection. On the basis of results presented in the next section we propose that the largest portion of the polar cap maps to a normal, taildirected lobe consisting of open but dormant field lines, as illustrated in Figure 6a. The dormancy of the field lines and hence the convection in this region is indicated by the unshaded area tailward of the convection cells in Figure $6 b$.

Application of Figure $6 a$ to the results in Figure 5 is straightforward. The strong, steady reverse convection in the summer hemisphere is attributed primarily to overdraped lobe cells, as in Figures $6 a-6 b$. Addition of $B_{y}$ effects to the above topology will cause one merging cell to increase in potential with respect to the other, as discussed earlier. Both of these effects are apparent in Figures $5 d$ and $5 e$. As $B_{y}$ changed from positive to increasingly negative values, the southern hemisphere high-latitude negative cell grew in area and strength, at the expense of the positive cell. Figure $5 f$ appears to be an exception to this case, but the relative strength of the convection cells in that plot is somewhat uncertain due to the assimilation of ground magnetometer data only.

Reverse convection in the southern hemisphere is the most obvious manifestation of the large positive $B_{3}$ component, but other signatures may exist. We pointed out the possibility of an embedded viscous cell in Figure 3a. Mitchell et al. [1987] have shown that the low-latitude boundary layer is substantially thicker during northward IMF than during southward IMF. This may allow for expansion of the viscous interaction region along the flanks of the magnetopause when the IMF is strongly northward (P. H. Reiff, private communication, 1992). Some indication of expanded low-latitude cells exists in Figure 5d. Although these cells are not as evident in Figure 5e, the high-resolution IDM data (not shown) for Figures $5 e$ (and $5 d$ ) indicate that cells with antisunward flow at high latitudes and sunward flows at lower latitudes existed equatorward of the reverse convection cells. If these cells are viscous in nature, their spatial footprint in the ionosphere is unusually large, consistent with Mozer [1984] and Heelis et al. [1986] who show larger than average viscous values $(\sim 10-15 \mathrm{kV})$ for northward IMF situations. The positive cell at $0200 \mathrm{MLT}$ and $80^{\circ}$ magnetic latitude in Figure $5 f$ is only defined by a few magnetometer stations, while the negative cell at dusk near $70^{\circ}$ latitude is even more uncertain. A sensitivity study shows that these low-latitude cells are not the result of the initial electric potential model. However, a portion of the $50-\mathrm{kV}$ voltage in the low-latitude cells may be associated with viscouslike interactions, although $50 \mathrm{kv}$ is well above previously reported values for northward IMF. The large voltages and subsequent dynamics of these cells lead us to propose that these cells may be the result of enhanced merging brought about by the increasing magnitude of $B_{y}$, as we discuss next.

\subsection{IMF Regime: $B_{y}<0, B_{z}>0\left|B_{y} / B_{z}\right|$ Increasing}

Figure 7 shows the evolution of convection between $1120 \mathrm{UT}$ and $1535 \mathrm{UT}$, during a period of increasing ratio $\left|B_{\mathbf{y}} / B_{\mathbf{z}}\right|$. In the three hours prior to this interval, $B_{\mathbf{z}}$ had been stable at nearly $+20 \mathrm{nT}$, while $B_{y}$ had become increasingly negative. As the interval progressed, the magnitude of $B_{y}$ approached and then exceeded that of $B_{2}$. Dramatic convection changes occurred just as the ratio $\left|B_{y} / B_{z}\right|$ exceeded unity.

Southern hemisphere. At $1120 \mathrm{UT}$, as the ratio $\left|\mathrm{B}_{\mathbf{y}} / \mathrm{B}_{\mathbf{z}}\right|$ approached unity, the DMSP satellite (Figure 7a) was skimming just poleward of $65^{\circ}$ magnetic latitude in the southern hemisphere providing very little to the determination of the convection pattern. The primary convection features at $1120 \mathrm{UT}$ were similar to those at 1040 UT (Figure 5f) and consisted of a set of slightly asymmetric reverse convection cells situated at high latitudes and a set of cells with convection in the normal sense just tailward of the reversed set. We interpret the 1120 UT reverse convection cells as predominantly lobe convection. They correspond to the compact convection cells in Figure $6 b$. In addition to the reverse cells the 1120 UT pattern has spatially larger cells that extend toward the nightside. Within $10 \mathrm{~min}$ after $B_{y}$ achieved the same magnitude as $B_{z}$, the positive cell of the reverse convection pair weakened and significantly contracted. By 1145 UT (Figure $7 b$ ) the positive cell had nearly disappeared, while the negative potential high-latitude cell had strengthened. It is possible that the increasing $\left|B_{y} / B_{z}\right|$ ratio established a new magnetopause merging site on closed dayside or flank field lines that transferred newly opened flux across the high-latitude region, thus contributing open flux to a pair of normal merging cells that ultimately spanned the entire polar cap. The new negative merging cell engulfed the existing negative lobe cell (Figures $7 b-7 d$ ), while the new positive merging cell formed on the dawnside of the negative cell, where it would be expected for normal (not reverse) convection. 
Between 1120 UT and 1240 UT the magnitude of the increasingly negative $B_{y}$ component became significantly larger than $B_{2}$. Within that interval the reverse convection configuration virtually disappeared (Figure $7 d$ ). Meanwhile, the positive nightside cell strengthened and expanded and by 1240 UT the flow across much of the polar cap took on an antisunward component (Figure $7 d$ ). The bulk of the transition was achieved less than $60 \mathrm{~min}$ after the $\left|B_{y} / B_{z}\right|$ ratio exceeded unity. Evidence of simultaneously enhanced merging in the northern hemisphere is discussed in the next subsection. Despite the fact that the ratio continued to increase after 1215 UT the convection pattern stayed in essentially a stable configuration after that time. This seems to indicate that a $\left|B_{y} / B_{z}\right|$ ratio close to unity is critical in determining the configuration of high-latitude convection when the IMF is northward. It may be the dividing point between what were formerly considered patterns for northward and southward IMF, at least near solstice. Thus normal two-cell convection exists [Iijima and Shibaji, 1987; Crooker, 1988; McCormac et al., 1991] for a broad range of IMF orientations. The final state of convection achieved from the transition most closely resembles the patterns derived by FriisChristensen et al. [1985] for $B_{z}>0, B_{y}<0$. The plots in Figure 7a-7f are crucial in showing how the transition from reverse convection to normal convection occurred.

At 1400 UT the broad scale of the positive dawn cell (Figure $7 e$ ) was confirmed by a lower-latitude ground magnetometer data station located at $64^{\circ}$ magnetic latitude and 0100 MLT. The last element of the convection series (Figure 7f) shows the state of the high-latitude convection achieved for 5-min average IMF values of $B_{x}=0.0, B_{y}=-30.9 n T$, and $B_{2}=2.1 \mathrm{nT}$ at $1535 \mathrm{UT}$. The cross-polar-cap potential difference associated with this east-to-west IMF was at least $75 \mathrm{kV}$ in the southern hemisphere (and probably closer to $100 \mathrm{kV}$, given that sensitivity studies of the AMIE procedure show that use of ground magnetometer data alone for AMIE mapping during large $B_{z}$ negative conditions can underestimate the cross-polar-cap potential difference by approximately 20\%). Even for $\mathrm{B}_{\mathbf{z}}>0$, the flow across the polar cap had an antisunward component, but as was the case at $1240 \mathrm{UT}$, the flow rotated and constricted slightly to produce a dawn-to-dusk flow component in the region tailward of the 0600-1800 MLT line. This interval provides a unique opportunity to study rapid convection reorganization that is attributable more to the variations in relative magnitudes of IMF components than to variations in any individual IMF component.

Our final point regarding this event concerns Heppner and Maynard's [1987] distorted two-cell patterns. If a satellite were to make repeated passes over the transitioning patterns of Figure $7 a-7 f$, we assert that the empirical pattern obtained after averaging the associated electric fields would be similar to a southern hemisphere version of Heppner and Maynard's distorted two-cell pattern for $B_{z}>0$ and $B_{y}<0$. It is thus possible that some of the strong distortion in the Heppner and Maynard two-cell patterns is an average representation of a set of transitory convection states like those mapped here. This does not imply, however, that distorted two-cell patterns are associated only with rapid IMF changes. Knipp et al. [1991] show distorted two-cell patterns that exist for periods of several hours.

Northern hemisphere. Now we consider the northern hemisphere convection for a subset of the period just dis- cussed, focusing on the times for which we have IDM data. At 1210 UT (Figure 7g) we see a general continuity of several of the features mapped at 1030 UT (Figure $5 c$ ), although the potential drop nearly doubled during the interval. Areas of weak negative potential were spread across the dusk sector and a round positive potential cell dominated the polar cap. What is different in the 1210 UT pattern and possibly associated with antisymmetric developments in the southern hemisphere (see Figure $7 c$ ) is the strong negative potential cell situated well tailward of the positive cell. The development of this region suggests merging was initiated at or just prior to $1210 \mathrm{UT}$. The negative cell is defined by the IDM data as well as the ground magnetic perturbations (not shown). Uncalibrated northern hemisphere DMSP imagery (not shown) provides clear evidence of regions of auroral brightening consistent with substorm onset at $1210 \mathrm{UT}$. After $1210 \mathrm{UT}$ we observe an expansion and strengthening of the entire convection pattern (Figures $7 h$ and $7 i$ ). Evidence of this expansion comes from both the IDM data and the ground magnetometers. The tailward negative-potential cell of Figure $7 g$ expanded toward the dayside as the $\left|B_{y} / B_{z}\right|$ ratio increased beyond unity (as did the positive tailward cell in the southern hernisphere).

The developments depicted in Figure 7 show a surprising degree of interhemispheric similarity which increases with time (but not conjugacy, since the development is mirror image and thus not on conjugate field lines). $B_{y} 1535$ UT both hemispheres contained cells that can be described as "crescent" and "round," each containing nearly equal potential, thus indicating merging as the primary convection driver. We attribute this development to the increasing importance of the $B_{y}$ component. As the $B_{y}$ magnitude grew, the convection strength in both hemispheres also increased. By $1535 \mathrm{UT}$, little interhemispheric difference in voltage or convection configuration was evident. Nearly $80 \mathrm{kV}$ of cross-polar-cap voltage was associated with almost purely eastward IMF ( $\left.B_{x}=0 n T, B_{y}=-30.9 n T, B_{z}=2.1 n T\right)$. Freeman et al. [1993] have commented that the transition to two-cell convection preceded the southward turning. This is evident from Figure 7 . The $B_{x}$ component, while probably contributing to interhemispherical convection asymmetry prior to $1400 \mathrm{UT}$, became negligible after $1400 \mathrm{UT}$ and was not a likely contributor to the convection configuration at 1535 UT. We note that the two-cell nature of the patterns we map at $1535 \mathrm{UT}$ is somewhat different than a standard southward IMF convection pattern. The final result at 1535 UT (Figure $7 i$ ) is a near-normal two-cell pattern with a cross-polar-cap potential drop of $93 \mathrm{kV}$. The flow pattern across the polar cap is clearly antisunward, but the convection is centered at. unusually high latitudes, consistent with a smaller polar cap for northward IMF.

Much of the interhemispherical asymmetry which we have attributed to the effects of overdraping (Figures 5 and 6 and associated discussion) disappeared as the $\left|B_{y} / B_{z}\right|$ ratio increased beyond unity. This is an important point. As we depict in Figure $6 a$, a portion of the southern hemisphere lobe flux was draped over the dayside, thereby reducing southern hemisphere tail lobe magnetic pressure. As the magnitude of $B_{y}$ increased, both open-to-open and closedto-open merging may have begun equatorward of the cusp. The former would act to return the overdraped lobe flux to the tail, while the latter would initiate normal convection adding flux to both tails. Evidence of enhanced tail merg- 


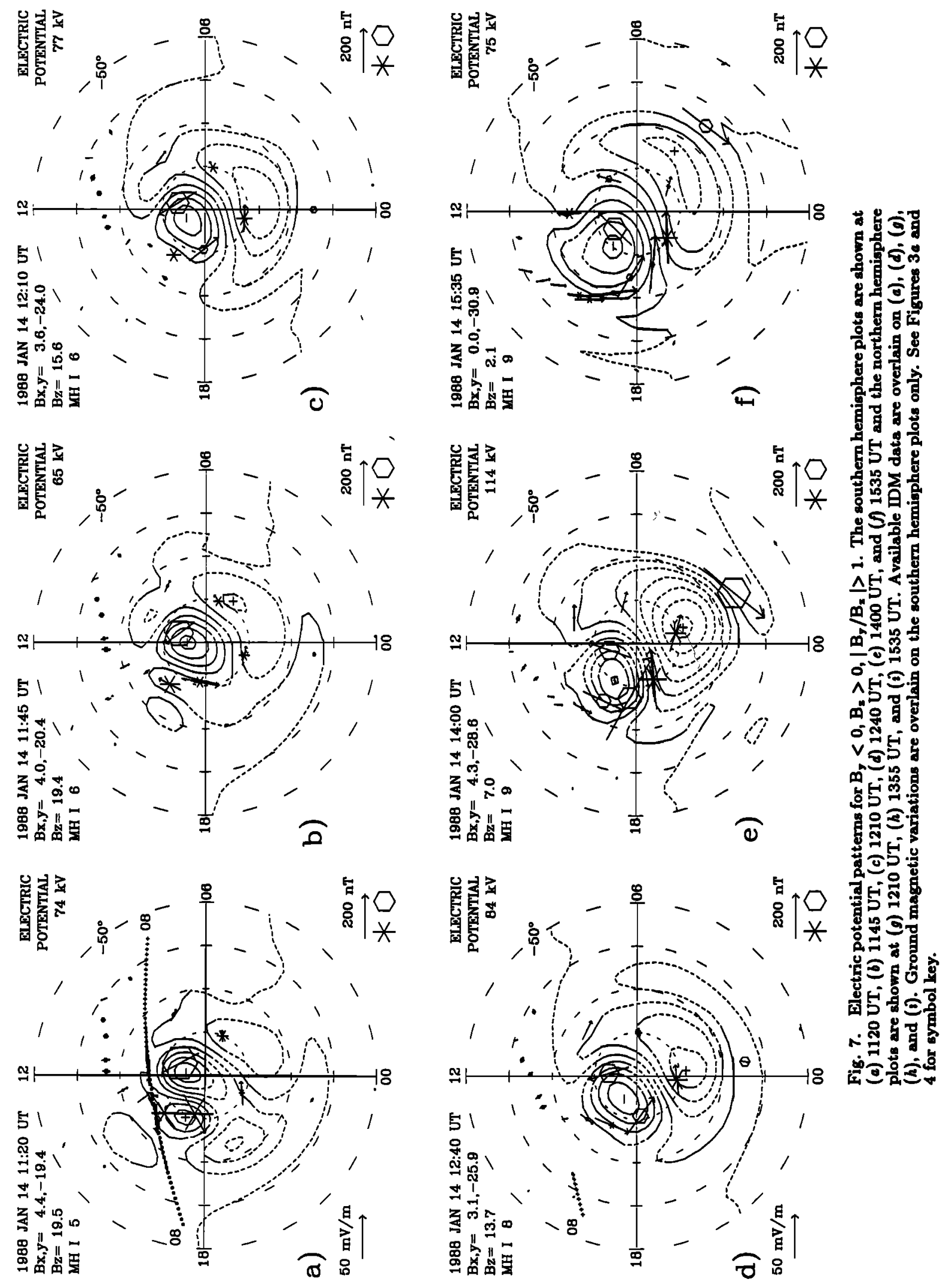



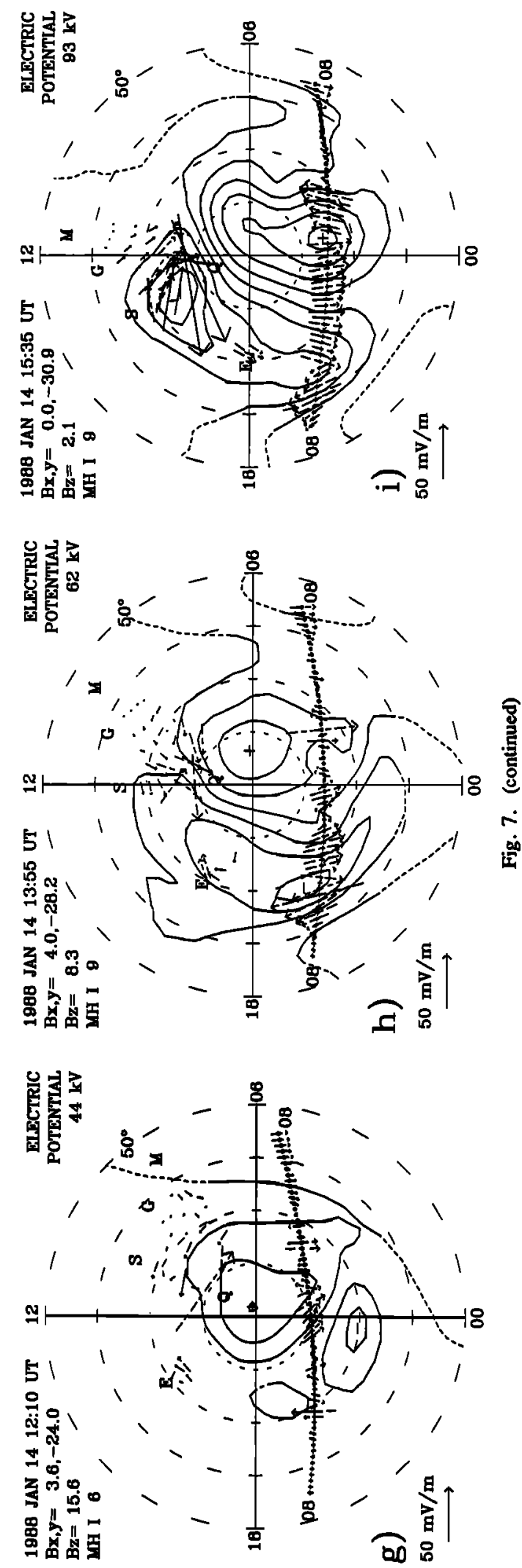

ing in both hemispheres is seen in the plots of Figure 7. Further evidence is seen in the rise of the AE index in the 1200 UT-1500 UT interval (see Figure $2 h$ ). Thus it appears that cessation of reverse convection and overdraping was a contributing factor to substorm initiation for the solstice conditions we describe here: $\left|B_{y} / B_{z}\right|>1$ and $B_{z}>0$.

\subsection{IMF Regime $B_{y}<<0, B_{z}<0,\left|B_{y} / B_{z}\right|>1$}

$A$ brief look at the northern hemisphere's convection as the IMF turned southward completes this paper's description of the ionospheric convection response to the January 14, 1988, magnetic cloud. At 1550 UT the IMF turned southward, but the convection retained the dominant features acquired during the previous interval of large negative $B_{y}$ and decreasingly positive $B_{2}$. Figures $8 a-8 c$ illustrate the slow transition to the more normal two-cell convection pattern usually associated with southward IMF. Figures $8 d-8 f$ show the associated ground magnetic deviations.

At $1600 \mathrm{UT}$ and 1640 UT (Figure $8 a$ and $8 b$ ), two of the features mapped in the previous convection series in the northern hemisphere (Figures $7 \mathrm{~g}-7 \mathrm{i}$ ) are still evident: the evening crescent cell and the morning round cell. The continuity of these cells through $1640 \mathrm{UT}$ (Figure $8 b$ ) suggests that some element of the lobe convection continued to occur much as it did prior to the southward turning of the IMF. However, the increase in magnetic deviations at 1640 UT, especially in the dawn and midnight sectors, attest to increasing electrojet activity in those regions. The activity continued to expand equatorward (Figure $8 f$ ) through 1720 UT as the magnitude of $B_{2}$ grew. The dawn region perturbations at $1640 \mathrm{UT}$ and $1720 \mathrm{UT}$ suggest very strong currents, but as indicated in the $1720 \mathrm{UT}$ plot (Figure $8 \mathrm{c}$ ), the accompanying electric fields were weak in the vicinity of the satellite track. This is consistent with increasing conductivity and currents associated with substorm particle injection. Increasing particle precipitation is suggested by the rise in the logarithmic hemispheric power index which occurred as the $B_{2}$ component became increasingly negative. The twocell convection pattern in Figure $8 c$ is representative of the convection configuration and strength mapped for the subsequent 17 hours of southward IMF.

\section{SUMMary}

\subsection{General Comments}

The passage of a interplanetary magnetic cloud, characterized by strong, slowly varying IMF conditions, has allowed us to investigate the configuration and strength of convection under $\mathrm{B}_{2}$ northward conditions. We have supplemented data sets from the GISMOS campaign of January 14-15, 1988, with DMSP IDM data, digisonde data, and radar and ground magnetometer observations from both hemispheres to produce one of the most comprehensive data sets yet assembled for the study of the convection response to solar wind variations. Based on this data set, we have shown that the polar cap convection was far from conjugate during most of the interval of northward IMF. The data set has also allowed us to follow the development and decay of convection patterns and portray the ionospheric convection patterns associated with the evolution to and from reverse convection in the southern hemisphere. We also demonstrate that this evolution took place while the northern hemisphere convection remained in a normal-to-quiet state. Some of the vari- 

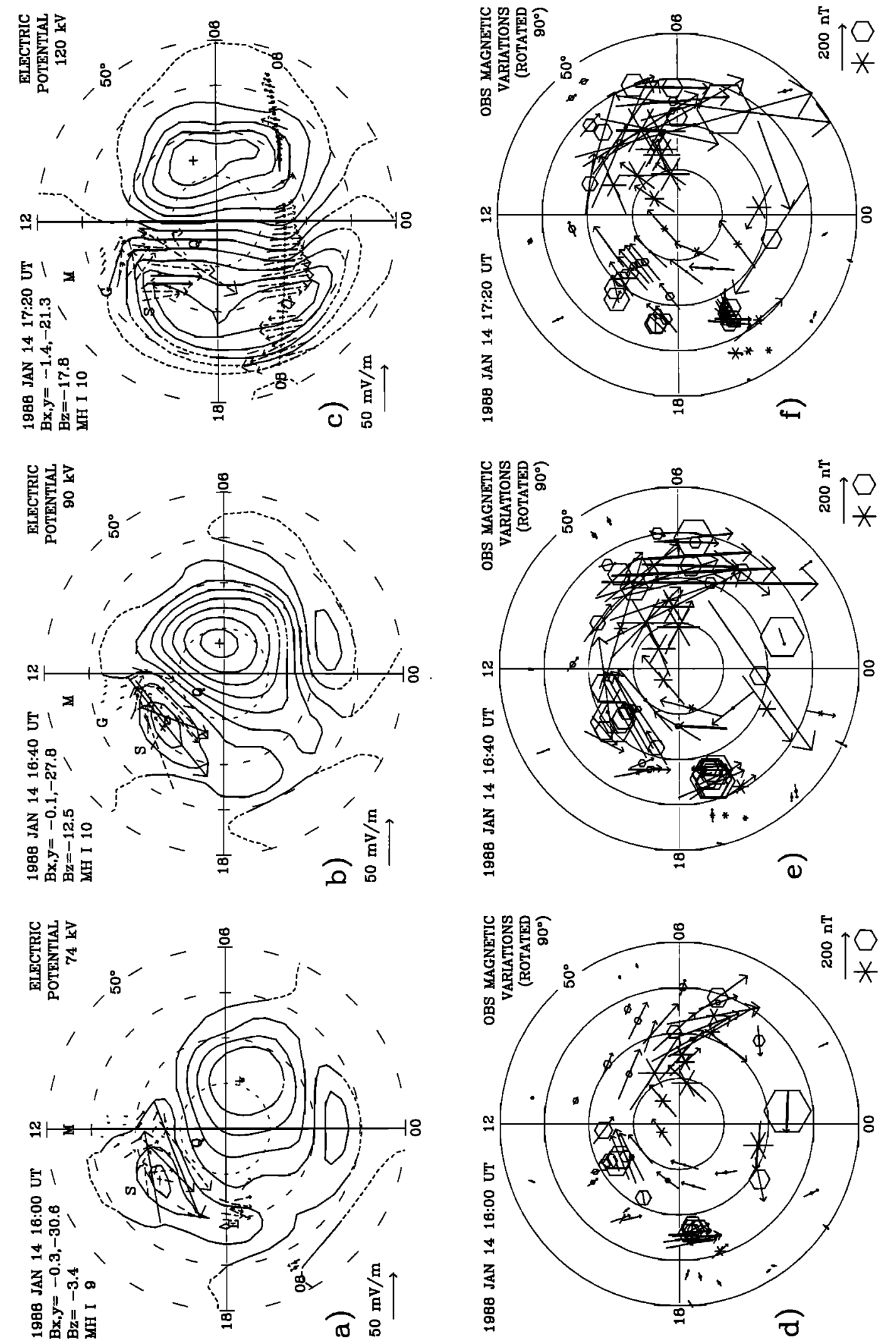

年焉

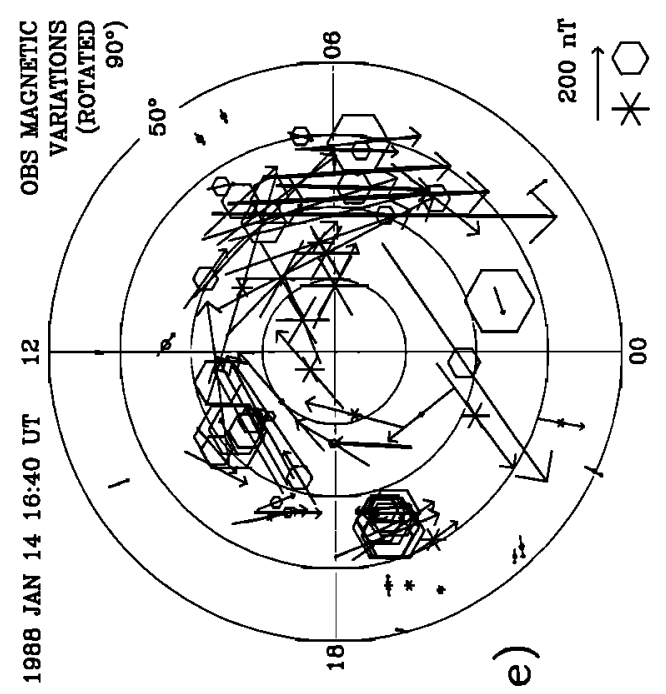

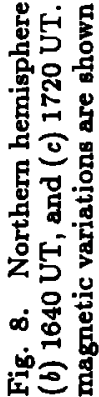

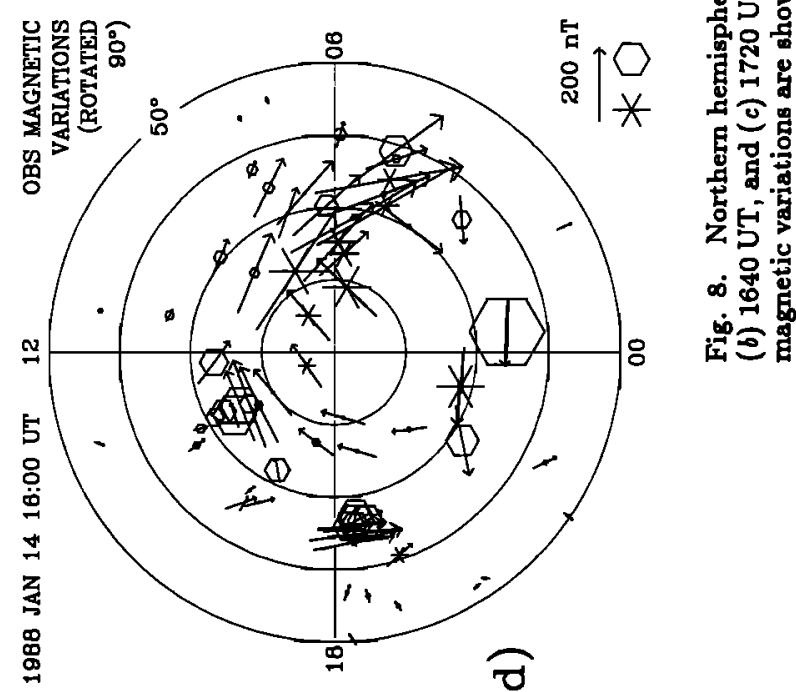


ations presented here are reflected in the models presented by Potemra et al. [1984], Friis-Christensen et al. [1985], and Heppner and Maynard [1987] and we have discussed them accordingly. We do not dismiss any of these patterns. Rather, we have attempted to attach physical significance to the differences in these results, especially to the extreme distortion in the Heppner-Maynard patterns.

As mentioned in the introduction, Freeman et al. [1993] and Farrugia et al. $[1993 a, b]$ have discussed the convection during this interval in terms of the magnetic cloud features. We have interpreted the convection patterns associated with the magnetic cloud within the general framework of a merging model. Crooker [1992] has recently updated this model to include the phenomenon of overdraping for northward IMF. During a significant portion of January 14, 1988, we believe the overdraped model provides the best interpretation for most of the interhemispherical asymmetries we depict. The northward IMF patterns show strong interhemispheric asymmetry, consistent with the predicted existence of lobe cell(s) in the summer, $B_{\mathbf{x}}$-favored hemisphere only, combined with weak merging cells in both hemispheres. The AMIE procedure applied to this interval provides a semiquantitative determination of the flux circulating in the predicted lobe cells compared to that in merging cells. The derived patterns also indicate that while reverse convection cells circulated in a small area confined to the dayside of the polar cap, presumably mapping in part to lobe fields that drape over the dayside of the magnetopause, a sizeable portion of the nightside polar cap existed in a near-dormant condition.

During the prolonged period of northward IMF, significant variations were introduced by the $B_{y}$ component and the relative magnitudes of the $B_{y}$ and $B_{z}$ components. Our results suggest that at solstice the ratio of IMF $\left|B_{y}\right| / B_{2}$ $=1$ marks the dividing point between reverse and normal convection, implying that normal convection in the southern hemisphere exists three quarters of the time and not half of the time as it would if the dividing point were $B_{z}=0$. Thus it appears that a unitary value of the $\left|B_{y} / B_{z}\right|$ ratio is critical in separating reverse convection from normal convection.

\subsection{Specific Findings}

Between $0300 \mathrm{UT}$ and $0500 \mathrm{UT}$ when the $\mathrm{B}_{\mathrm{y}}$ component was large relative to the $B_{z}$ component $\left(\left|B_{y} / B_{z}\right|>1\right)$, the southern hemisphere experienced strong (nearly single cell) lobe convection, which resulted in a $30-\mathrm{kV}$ excess in potential compared to the northern hemisphere. Although the northern hemisphere was apparently not involved in lobe merging, the convection in that hemisphere was not in a ground state. Normal merging convection provided simultaneous cross-polar-cap potential drops of $\sim 50 \mathrm{kV}$ in both hemispheres.

While the $B_{x}$ and $B_{z}$ components were positive and the $B_{y}$ component was small, the effects of overdraping are most evident. The southern polar cap, which was tilted toward the Sun, experienced strong, organized convection, while the oppositely tilted pole experienced significantly less ordered ion flow and reduced convection strength. As $B_{z}$ increased and $B_{y}$ decreased in magnitude, an additional lobe cell developed in the southern hemisphere. The growth of this cell ultimately produced strong reverse (double cell) convection with a dusk-to-dawn potential drop of $>120 \mathrm{kV}$. This convection was confined to magnetic latitudes greater than $75^{\circ}$. At the same time the northern hemisphere convection achieved its most relaxed state with a cross-polar-cap potential drop of $25 \mathrm{kV}$.

While the $B_{z}$ component remained positive but the $B_{y}$ component magnitude grew, some indication of increased merging cell activity became evident in both hemispheres. As the ratio, $\left|B_{y} / B_{z}\right|$, again exceeded unity, a rapid and very dramatic restructuring of the convection configuration occurred. Within an hour the southern hemisphere convection changed from a reverse configuration to a more normal configuration encompassing the previously dormant nightside of the polar cap. A similar reconfiguration was evident in the northern hemisphere. A substantial cross-polarcap potential drop ( $80-100 \mathrm{kV}$ ) arose from convection that was driven by a strong IMF $B_{y}$ component. The convection strength was similar in each hemisphere but was not symmetric.

The transition to $B_{2}$ southward did not produce an immediate sharp change to normal two-cell convection. Rather a slow transition with development of an enhanced dawn cell in the northern hemisphere occurred.

We have demonstrated many of the strengths and applications of the AMIE procedure. The procedure has proved to be a useful tool in analyzing convection response to both slow and moderately paced variations in the IMF. A future paper provides more in-depth documentation of a response to rapid solar wind variations.

Acknowledgments. No analysis of this magnitude can be undertaken without the generous cooperation of all data providers. Incoherent scatter radar data for Sondrestrom (Sondre Stromfjord), Millstone Hill, and EISCAT were provided by the CEDAR (Coupling, Energetics and Dynamics of Atmospheric Regions) data base located at the National Center for Atmiospheric Research (NCAR). Sondrestrom incoherent scatter radar and the Millatone Hill radar are supported by the National Science Foundation (NSF) contractual agreement ATM 8822560; the CEDAR data base and NCAR are also supported by NSF. The EISCAT Scientific Association is supported by Centre National de la Recherche Scientifique of France, Suomen Akateiis of Finland, Max-Planck-Gesellschaft of Germany, Norges Almenvitenskapelige Forskningsrad of Norway, Naturvetenskapliga Forskningsradet of Sweden, and the Science and Engineering Research Council of the United Kingdom. The Johns Hopkins University/Applied Physics Laboratory HF radar located at Goose Bay Labrador is aupported in part by the NSF Division of Atmospheric Sciences under NSF grant ATM- 9003860 and in part by the National Aeronautics and Space Administration (NASA) under NASA grant NAG5-1099. Defense Meteorological Satellite Program (DMSP) ion drift meter data were processed by the University of Texas at Dallas Space Sciences Center under Air Force Phillips Laboratory, Geophysics Directorate contract F19628-90-K-0002. We wish to thank R. A. Heelis for his assistance in interpreting these data. $T$. Wilson of the National Geophyaical Data Center in Boulder, Colorado, was instrumental in providing us with initial electron precipitation measurements from the DMSP satellite. The Qanaq digisonde is operated with support from the Danish Meteorological Institute and by permission from the Commission for Scientific Research in Greenland. One hundred and two ground magnetic observatories contributed to this study. Fifty-six of these were processed through the World Data Center $A$ in Boulder. We are indebted to L. Morris of that facility for selecting all the digital data. R. Farmer of the Air Force Academy helped to digitize analog data. We want to extend special thanks to $R$. Schlich and J. Bitterly of the Institut de Physique du Globe de Strasbourg, Strasbourg, France, for submitting magnetometer data to the World Data Center for Martin de Vivies (AMS), Port Alfred (CZT), Port-aux-Francais (KGL), and Dumont d'Urville (DRV). The $D_{\text {at }}$ index used in the analysis of the ground magnetometer stations was provided by $\mathrm{T}$. Kamei of the World Data 
Center $\mathrm{C} 2$ at Kyoto University and by M. Sugiura of Tokai University in Japan. The analysis for the southern hemisphere was aided by access to ground magnetometer data provided by $L$. Lanzerotti and A. Wolfe of AT\&T Bell Laboratories, USA. T. Rosenberg of the University of Maryland provided quick access to South Pole and McMurdo data. The assistance of Australian Antarctic Division staff and Australian National Antarctic Research Expedition (ANARE), Auroral and Space Physics expeditioners is gratefully acknowledged. The following individuals provided drafts and/or preprints of articles related to this publication: N. Crooker, G. Crowley, J. Cumnock, C. Farrugia, and $M$. Freeman. We have made extensive use of statistical models provided by N. Maynard, T. Fuller-Rowell, D. Evans, and J. Foster in this study. We would like to thank R. Lepping of NASA Goddard Space Flight Center for providing the IMP 8 magnetic field data, A. Lazarus of the Massachusetts Institute of Technology for providing IMP 8 plasma data, R. Johnson of the Space Physics Laboratory of the University of Michigan for help in obtaining the IMF data, and D. Sibeck of the Johns Hopkins University/Applied Physics Laboratory for help in obtaining the plasma data. N. Crooker was supported by NSF grant ATM 91-17484. O. de la Beaujardiere was supported by NSF grant ATM 91-02439. G. Crowley was supported by the Air Force Phillips Laboratory Geophysics Directorate under contract F19628-90-K-0005 and the Air Force Office of Scientific Research Task 2310G9. D. Knipp, B. Emery, and A. Richmond were supported by NASA Work Order W-17384. D Knipp was also supported by the F. J. Seiler Research Laboratory at the Air Force Academy.

The Editor thanks J. L. Burch and another referee for their assistance in evaluating this paper.

\section{REFERENCES}

Ahn, B.-H., H. W. Kroehl, Y. Kamide, and D. J. Gorney, Estimation of ionospheric electrodynamic parameters using ionospheric conductance deduced from bremsatrahlung $X$ ray image data, J. Geophys. Res., 94, 2565, 1989.

Akasofu, S.-I., B.-H. Ahn, Y. Kamide, and J. H. Allen, A note on the accuracy of the auroral electrojets indices, J. Geophys. Res., 88, 5769, 1983.

Baker, K. B., R. A. Greenwald, J. M. Ruohoniemi, J. R. Dudeney, M. Pinnock, N. Mattin, and J. M. Leanard, PACE, Polar Anglo-American Conjugate Experiment (abstract), EOS Trans. $A G U, 70,785,1989$.

Buchau, J., B. W. Reinisch, D. N. Anderson, E. J. Weber, and C. G. Dozois, Polar cap convection measurements and their relevance to the real-time modelling of the high latitude ionosphere, Radio Sci., 29, 521, 1988.

Burch, J. L., P. H. Reiff, J. D. Menietti, R. A. Heelis, W. B. Hanson, S. D. Showhan, E. G. Shelley, M. Sugiura, D. R. Weimer, and J. D. Winningham, IMF $B_{y}$-dependent plasma flow and Birkeland currents in the dayside magnetosphere, 1 , Dynamics Explorer observations, J. Geophys. Res., 90, 1577, 1985.

Burke, W. J., M. C. Kelley, R. C. Sagalyn, M. Smiddy, and S. T. Lai, Polar cap electric field structures with a northward interplanetary magnetic field, Geophys. Res. Lett., 6, 1, 1979.

Burke, W. J., The polar cap with northward IMF: What I think I know, in Physics of Space Plasmas, SPI Conf. Proc., 8, 153, 1989.

Burke, W. J., E. M. Basinska, N. C. Maynard, W. B. Hanson, J A. Slavin, and J. D. Winningham, Polar cap potential distributions during periods of positive IMF $\mathrm{B}_{y}$ and $\mathrm{B}_{\mathrm{z}}, \mathrm{J}$. Atmos. Terr. Phys., in press, 1993.

Burlaga, L. F., R. P. Lepping, and J. A. Jones, Global configuration of a magnetic cloud, in Physics of Magnetic Flux Ropes, Geophys. Monogr. Ser., vol. 58, edited by C. T. Russell, E. R. Priest, and L. C. Lee, p. 373, AGU, Washington, D. C., 1990.

Bythrow, P. F., W. J. Burke, T. A. Potemra, L. J. Zanetti, and A. T. U. Lui, Ionospheric evidence for irregular reconnection and turbulent plasma flows in the magnetotail during periods of northward interplanetary magnetic field, J. Geophys. Res., 90, 5319, 1985.

Cannon, P. S., B. W. Reinisch, J. Buchau, and T. W. Bul- lett, Response of the polar cap region convection direction to changes in the interplanetary magnetic field: Digisonde measurements in northern Greenland, J. Geophys. Res., 96, 1239, 1991.

Carlson, H. C., R. A. Heelis, E. J. Weber, and J. R. Sharber, Coherent mesoscale convection patterns during northeast interplanetary magnetic field, J. Geophys. Res., 99, 14,501, 1988.

Coley, W. R., R. A. Heelis, and W. B. Hanson, Ionospheric convection signatures and magnetic field topology, J. Geophys. Res., 92, 12,352, 1987.

Cowley, S. W., Asymmetry effects associated with the Xcomponent of the IMF in a magnetically open magnetosphere, Planet Space Sci., 29, 809, 1981.

Crooker, N. U., Dayside merging and cusp geometry, J. Geophys. Res., 84, 951, 1979.

Crooker, N. U., Mapping the merging potential from the magnetopause to the ionosphere through the dayside cusp, J. Geophys. Res., 99, 7338, 1988.

Crooker, N. U., Reverse convection, J. Geophys. Res., 97, $19,363,1992$.

Crowley, G., C. G. Dozois, B. W. Reinisch, and J. Buchau, Polar cap convection for Ba northward, Geophys. Res. Lett., 19, 657, 1992.

Cumnock, J. A., R. A. Heelis, and M. R. Hairston, The response of the ionospheric convection pattern to a rotation of the IMF on January 14, 1988, J. Geophyo. Reo., 97, 19,449, 1992.

Dungey, J. W., Interplanetary magnetic field and the auroral zones, Phys. Rev. Lett., 6, 47, 1961.

Dungey, J. W., The structure of the ionosphere, or adventures in velocity space, in Geophysics: The Earth's Environment, edited by C. DeWitt, J. Hiebolt, and A. Lebeau, pp. 526-536, Gordon and Breach, New York, 1963.

Emery, B. A., et al., Electric potential patterns deduced for the SUNDIAL period of September 23-26, 1986, Ann. Geophys., 8, 399, 1990.

Farrugia, C. J., L. F. Burlaga, M. P. Freeman, V. Osheravich, I. G. Richardson, R. P. Lepping, and A. Lazarus, A study of an expanding interplanetary magnetic cloud and its interaction with the Earth's magnetosphere: The interplanetary aspect, J. Geophys. Res., 98, 7621, 1993 a.

Farrugia, C. J., M. P. Freeman, L. F. Burlaga, R. P. Lepping, and $K$. Takahashi, The Earth's magnetosphere under continued forcing: Substorm activity during the passage of an interplanetary magnetic cloud, J. Geophys. Res., 98, 7657, 19936.

Foster, J. C., J. M. Holt, R. G. Musgrove, and D. S. Evans, Ionospheric convection associated with discrete levels of particle precipitation, Geophys. Res. Lett., 19, 656, 1986.

Freeman, M. P., C. J. Farrugia, L. F. Burlaga, R. P. Lepping, M. E. Greenspan, and J. M. Ruohoniemi, The interaction of a magnetic cloud with the Earth: Ionospheric convection in the northern and southern hemispheres for a wide range of quasisteady interplanetary magnetic field conditions, $J$. Geophys. Res., 98, 7633, 1993.

Friis-Christensen, E., Y. Kamide, A. D. Richmond, and S. Matsushita, Interplanetary magnetic field control of high-latitude electric fields and currents determined from Greenland magnetometer data, J. Geophys. Res., 90, 1325, 1985.

Fuller-Rowell, T. J., and D. S. Evans, Height-integrated Pedersen and Hall conductivity patterns inferred from the TIROSNOAA satellite data, J. Geophyo. Res., 92, 7606, 1987.

Greenwald, R. A., K. B. Baker, R. A. Hutchins, and C. Hanuise, An $\mathrm{HF}$ phased array radar for studying small scale structure in the high-latitude ionosphere, Radio Sci., 20,63, 1985.

Heelis, R. A., and M. R. Hairston, Studies of ionospheric dynamice utilizing data from DMSP, AFSC-GL-TR-90-0047 (I), 1990.

Heelis, R. A., and W. B. Hanson, High-latitude ion convection in the nighttime $F$ region, J. Geophys. Res., $85,1995,1980$.

Heelis, R. A., P. H. Reiff, J. D. Winningham, and W. B. Hanson, Ionospheric convection signatures observed by DE 2 during northward interplanetary magnetic field, J. Geophys. Res., 91, 5817, 1986.

Heppner, J. P., and N. C. Maynard, Empirical high-latitude electric field models, J. Geophys. Res., 92, 4467, 1987.

Hill, T. W., Theoretical models of polar-cap convection under 
the influence of northward interplanetary magnetic field, $J$. Atmos. Terr. Phys., in press, 1993.

Hoftman, R. A., M. Sugiura, N. C. Maynard, R. M. Candey, J. D. Craven, and L. A. Frank, Electrodynamic patterns in the polar region during periods of extreme magnetic quiescence, J. Geophys. Res., 99, 14,515, 1988.

Ijima, T., and T. Shibaji, Global characteristics of northward IMF-associated (NBZ) field-aligned currents, J. Geophys. Res., 92, 2408, 1987.

Irraelevich, P. L., I. M. Podgorny, A. K. Kuzmin, N. S. Nikolaeva, and E. M. Dubinin, Convection and field-aligned currents, related to polar cap arcs, during strongly northward IMF (11, January 1983), Planet. Space Sci., 96, 1317, 1988.

Jankowska, K., R. D. Elphinstone, J. S. Murphree, L. L. Cogger, D. Hearn, and G. Marklund, The configuration of the auroral

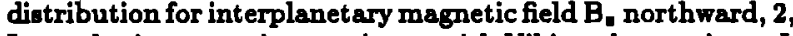
Ionospheric convection consistent with Viking observations, $J$. Geophyo. Res., 95, 5805, 1990.

Kamide, Y., and S.-I. Akasofu, Notes on the auroral electrojet indices, Rev. Geophys. Space Phys., 21, 1647, 1983.

Kamide, Y., and W. Baumjohann, Eatimation of electric fielda and currents from international magnetospheric study magnetogram data for the CDAW 6 interval: Implications for substorm dynamics, J. Geophys. Res., 90, 1305, 1985.

Kamide, Y., A. D. Richmond, and S. Matsushita, Estimation of ionospheric electric fields, ionospheric currents and fieldaligned currents from ground magnetic records, J. Geophys. Res., 86, 801, 1981.

Kamide, Y., J. D. Craven, L. A. Frank, B.-H. Ahn, and S.-I. Alkasofu, Modeling substorm current systems using conductivity distributions inferred from DE auroral images, J. Geophys. Res., 91, 11,235, 1986.

Knipp, D. J., A. D. Richmond, G. Crowley, O. de la Beaujardiere, E. Friis-Christensen, D. S. Evans, J. C. Foster, I. W. McCrea, F. J. Rich, and J. A. Waldock, Electrodynamics patterns for September 19, 1984, J. Geophys. Res., 94, 16,913, 1989.

Knipp, D. J., A. D. Richmond, B. Emery, N. U. Crooker, O. de la Beaujardiere, D. S. Evans, and H. Kroehl, Ionospheric convection response to changing $\mathrm{IMF}$ direction, Geophys. Res. Lett., 18, 721, 1991.

Knipp, D. J., B. A. Emery, A. D. Richmond, and M. R. Hairston, Mapping ionospheric convection response to IMF $B_{y}$ negative and $B_{2}$ positive conditions, J. Atmos. Terr. Phys., in press, 1993.

Luhmann, J. G., R. J. Walker, C. T. Russell, N. U. Crooker, J. R. Spreiter, and S. S. Stahara, Patterns of potential magnetic field merging sites on the dayside magnetopause, $J$. Geophys. Res., 89, 1739, 1984.

Meezawa, K., Magnetospheric convection induced by the positive and negative $Z$ components of the interplanetary magnetic field: Quantitative analysis using polar cap magnetic records, J. Geophy. Res., 81, 2289, 1976.

Mansurov, S. V., New evidence of a relationship between magnetic field in space and earth, Geomagn. Aeron., 4, 622, 1969.

Marklund, G. T., and L. G. Blomberg, On the influence of localized electric fields and field-aligned currents associated with polar arcs on the global potential distribution, J. Geophys. Res., 96, 13,977, 1991.

Marklund, G. T., L. G. Blomberg, T. A. Potemra, J. S. Murphree, F. J. Rich, and K. Stasjewicz, A new method to derive "instantaneous" high latitude potential distributions from satellite measurements including auroral imager data, Geophys. Res. Lett., 14, 439, 1987.

Marklund, G. T., L. G. Blomberg, J. S. Murphree, R. D. Elphinstone, L. J. Zanetti, R. E. Erlandson, I. Sandahl, O. De La Beaujardiere, O. Opgenoorth, and F. J. Rich, On the electrodynamical state of the auroral ionosphere during northward interplanetary magnetic field: A transpolar arc case study, $J$. Geophys. Res., 96, 9567, 1991.

McCormac, F. G., T. L. Killeen, and J. P. Thayer, The influence of IMF $B_{y}$ on the high-latitude thermospheric circulation during northward IMF, J. Geophys. Res., 96, 115, 1991.

McPherron, R. L., Physical processes producing magnetospheric substorms and magnetic storms, in Geomagnetism, vol. 4, edited by J. A. Jacobs, Pp. 592-739, Academic, San Diego, Calif., 1991.
Mishin, V. M., The magnetogram inversion technique and some applications, Space Sci. Rev., 59, 83, 1990.

Mishin, V. M., The magnetogram inversion technique: Applications to the problem of magnetospheric substorms, Space Sci. Rev., 54, 237, 1991.

Mishin, V. M., A. D. Bazarzhapov, and G. B. Shynev, Electric fields and currents in the earth's magnetosphere, in Dynamics of the Magnetoophere, edited by S.-I. Akasofu, pp. 249, D. Reidel, Norwell, Mass., 1979.

Mitchell, D. G., F. Kutchko, D. J. Williams, T. Eastman, L. A. Frank, and C. T. Russell, An extended study of the lowlatitude boundary layer on the dawn and dusk flanks of the magnetopause, J. Geophys. Res., 92, 7394, 1987.

Mozer, F. S., Electric field evidence on the viscous interaction at the magnetopause, Geophys. Res. Lett., 11, 135, 1984.

Potemra, T. A., L. J. Zanetti, P. F. Bythrow, and A. T. Y. Lui, $B_{\text {, }}$-dependent convection patterns during northward interplanetary magnetic field, J. Geophys. Res., 89, 9753, 1984.

Reiff, P. H., Sunward convection in both polar caps, J. Geophys. Res., 87, 5976, 1982.

Reif, P. H., and J. L. Burch, IMF $B_{y}$-dependent plasma flow and Birkeland currents in the dayside magnetosphere, 2, A global model for northward and southward IMF, J. Geophys. Res., 90, 1595, 1985.

Reiff, P. H., and J. G. Luhmann, Solar wind control of polar cap voltages, Soler Wind-Magnetosphere Coupling, edited by Y. Kamide and J. A. Slavin, Pp. 453-476, Terra Scientific, Tokyo, 1986.

Reinisch, B. W., New techniques in ground based ionospheric sounding and studies, Radio Sci., 21, 331, 1986.

Reinisch, B. W., K. Bibl, D. Kitrosser, G. Sales, J. Zhang, T. Bullet, and J. Rolls, The digisonde 256 sounder, WITS Handbook, vol. 2, edited by C. H. Liu, Pp. 350-360, University of Illinois, Urbana, 1989.

Rich, F. J., and M. S. Gussehoven, The absence of region 1/region 2 field aligned currents during prolonged quiet periods, Geophys. Res. Lett, 14, 689, 1987.

Richmond, A. D., Assimilative mapping of ionospheric electrodynamics, Adv. Space Res., 6, (6)59, 1992.

Richmond, A. D., and Y. Kamide, Mapping electrodynamic features of the high-latitude ionosphere from localized observations: Technique, J. Geophys. Res., 93, 5741, 1988.

Richmond, A. D., et al., Mapping electrodynamic features of the high-latitude ionosphere from localized observations: Combined incoherent scatter radar and localized observations: Measurements for January 18-19, 1984, J. Geophys. Res., $99,5760,1988$.

Richmond, A. D., et al., Global measures of ionospheric electrodynamic activity inferred from combined incoherent-scatter radar and ground magnetometer observations, J. Geophys. Rea., 95, $1061,1990$.

Ruohoniemi, J. M., R. A. Greenwald, K. B. Baker, J.-P. Villian, C. Haniuse, and J. Kelly, Mapping high-latitude plasma convection with coherent HF radars, J. Geophy Res., 94, 13,463, 1989.

Russell, C. T., The configuration of the magnetosphere, in Critical Problems of Magnetospheric Physics, edited by E. R. Dyer, Jr., pp. 1-16, National Academy of Sciences, Washington, D. C., 1972.

Siscoe, G. L., The magnetosphere: A union of inter-dependent parts (abstract), $E \Theta S$ Trans. $A G U ., 72,(17)$, Spring Meeting ouppl., 235, 1991.

Svalgaard, L., Sector atructure of the interplanetary magnetic field and daily variations of geomagnetic field at high latitudes, Geophys. Pap. R-6, Dan. Meteorol. Inst., Copenhagen, 1968.

Troshichev, O. A., Global dynamics of the magnetosphere for northward IMF conditions, J. Atmos. Terr. Phys., 52, 1135, 1990.

Zanetti, L. J., T. A. Potemra, J. P. Doering, J. S. Lee, J. F. Fennell, and R. A. Hoffman, Interplanetary magnetic field control of high-latitude activity on July $29,1977, J$. Geophys. Rea., 87, 5963, 1982.

Zhu, L., and J. R. Kan, Relationship between four-cell and distorted two-cell convection patterns during northward IMF, Geophys. Res. Lett., 17, 2325, 1990. 
B.-H. Ahn, Kyungpook National University, Taegu, Korea. G. B. Burns and R. J. Morris, Australian Antarctic Division, Kingston, Tasmania, Australia.

N. U. Crooker, Atmospheric Science Department, UCLA, Los Angeles, CA 90032.

G. Crowley, The Johns Hopkins University Applied Physics Laboratory, Laurel, MD 20723.

J. A. Cumnock and M. R. Hairston, University of Texas at Dallas, Richardson, TX 75080.

O. de la Beaujardiere, SRI International, Menlo Park, CA 37877.

W. F. Denig and F. J. Rich, Phillips Laboratory, Hanscom AFB, MA 01730.

B. A. Emery and A. D. Richmond, High Altitude Observatory, NCAR, Boulder, CO 80307-3000.

D. S. Evans and T. J. Fuller-Rowell, Space Environment Laboratory, NOAA, Boulder, CO 80303.

E. Friis-Christensen, Danish Meteorological Institute, Copenhagen, Denmark.

D. J. Knipp, Department of Physics, U.S. Air Force Academy, $\mathrm{CO} 80840$.

H. W. Kroehl, National Geophysical Data Center, Boulder, $\mathrm{CO} 80303$.

M. Lockwood, Rutherford-Appleton Laboratory, Chilton, Didcot, Oxon, England.
C. G. Maclennan, AT\&T Bell Laboratories, Murray Hill, NJ 07974.

A. McEwin, Bureau of Mineral Resources, Canberra, Australia.

V. Papitashvili and A. Zaitzev, IZMIRAN, Troitsk, Moscow Region, Russia.

R. J. Pellinen, Finnish Meteorological Institute, Helsinki, Finland.

A. S. Rodger, British Antarctic Survey, Cambridge, England.

J. M. Ruohoniemi, The Johns Hopkins University Applied Physics Laboratory, Laurel, MD 20723.

N. Sato, National Institute of Polar Research, Tokyo, Japan.

P. Sutcliffe, Hermanus Magnetic Observatory, Hermanus, South Africa.

L. Tomlinson, Institute of Geolofical and Nuclear Sciences Ltd., Christchurch, New Zealand.

O. Troshichev, Arctic and Antarctic Research Institute, St. Petersburg, Russia.

(Received September 24, 1992; revised March 5, 1993; accepted April 8, 1993.) 